\title{
Type 2 Diabetes and Developmental Origin of Non-Alcohol Fatty Liver Disease and Future Directions of Treatment
}

\author{
EI-Sayyad $\mathrm{HI}^{1 *}$ and El-Shahary EA ${ }^{2}$ \\ ${ }^{1}$ Department of Zoology, Faculty of Science, Mansoura University, Mansoura, Egypt \\ ${ }^{2}$ IBB University Yemen and King Khaled University, Saudia Mohayel College, KSA, Saudi Arabia
}

*Corresponding author: El-Sayyad HI, Department of Zoology, Faculty of Science, Mansoura University, Mansoura, Egypt, Tel: 0020502254850; E-mail: elsayyad@mans.edu.eg

Received date: September 19, 2016; Accepted date: September 29, 2016; Published date: October 06, 2016

Copyright: (C) 2016 El-Sayyad HI, et al. This is an open-access article distributed under the terms of the Creative Commons Attribution License, which permits unrestricted use, distribution, and reproduction in any medium, provided the original author and source are credited.

\begin{abstract}
Non-alcohol fatty liver disease is a large public health problem developed earlier during intrauterine life as a result of gestational or type 2 diabetes. The disease is associated with altered liver enzymes, lipid accumulation and hepatic steatosis due to hepatic de novo lipogenesis. Multiple factors are associated in the development of the disease such as peroxisome proliferator-activated receptor- $\gamma$ co-activator, B-cell dysfunction and abnormal metabolism of mitochondria, lysosomes, rough endoplasmic reticulum and Golgi complex. These factors are discussed in details. Different approaches of drug-treatment, phyto-\& gene therapy are illustrated. Role of type 2 or gestational diabetes on developmental origin of fatty liver. The interrelation-ship between type 2 diabetes and obesity and fetus's liver. Role of cytoplasmic organelles in de novo lipogenesis, inflammation, and hepatocyte cell death. Future direction of drug-treatment, phyto-and gene-therapy.
\end{abstract}

Keywords: Diabetes; Non-alcohol fatty liver disease; Mitochondria; Autophagy; Rough endoplasmic reticulum; Golgi complex; Drug; Phytotherapy

\section{Introduction}

The liver is the largest body organ composed mainly of hepatocytes. Embryologically, hepatocytes derived from the endodermal layer, meanwhile the stromal, stellate and Kuppfer cells and blood vessels, are from the mesoderm. The hepatocytes of the developing fetus have the capability to change into $\beta$-cell. According to Barker et al. [1], the developmental origins of adult disease started early in utero life. Epigenetic reprogramming during early life altered DNA transcription and gene expression into adulthood and contributed to disease susceptibility. In utero 'diabetic' environment facilitated the development of diabetes in the child. Gestational and type 2 diabetes altered the structures and functions of lysosomes, mitochondria, Golgi apparatus and rough endoplasmic reticulum leading to de nevo lipogenesis and development of non-alcohol fatty liver disease (NAFLD).

\section{Embryological origin of liver}

The liver is of vital important in metabolism, bile production, dietary metabolism, detoxification and glucose and blood homeostasis. Hepatocytes is the main cell components in the liver making about $70 \%$ of its content. Studies on animal models and in vitro cell culture showed that much of hepatogenesis is occurred through a developmental process as a result of interaction between the endoderm and mesoderm layer $[2,3]$.

Embryologically, the liver is endodermal origin. The development started by the liver diverticulum outlined by hepatoblasts that appear columnar and transformed to a pseudostratified epithelium [4]. The liver bud is lined by a basement membrane rich in laminin, collagen
IV, nidogen, fibronectin, and heparan sulfate proteoglycan [5]. The hepatoblasts then migrate and infiltrated the septum transversum, lose their epithelial morphology and reduce expression of E-cadherin following move away from the endoderm. Liver expansion depends on continuous interactions between hepatoblasts and adjacent mesodermal tissues [3]. The liver bud is coated peripherally by endothelial cells facilitates hepatoblast differentiation [6]. The septum transversum, the endothelial cells, and the hepatoblasts express hepatocyte growth factor (HGF). Between Embryonic stage 9.5 and 12.5 days prenatal in mice, the hepatoblasts possessed genes that are active during its maturation. The hepatoblasts are rich in rough endoplasmic reticulum and lipid vesicles, manifesting the hepatocyte differentiation process [7]. During liver development, the endothelial cell is originated from FOXA2+ endodermal-derived fetal hepatoblast which express KDR (VEGFR2/FLK-1). In vitro culture of KDR +FOXA2+ endoderm cells giving rise to hepatoblasts are found to generate functional endothelial cells [8].

The differentiation of hepatoblasts into hepatocytes make their first appearance at 13-d of mouse development through expression of albumin, cytokeratin-19 and a-fetoprotein. Overexpression of cytokeratin-19 is remarked in hepatoblasts aligned in close contact with the portal vein from mono-to bi-cell layer followed by regression with the advancement growth in the perinatal life [9]. Just before the parturition, the hepatocytes take the characteristic pattern structure of hepatic cords with bile canaliculi [10].

During 3-8 weeks postnatal mouse development, non-dependent sex genes are contributed in cell cycle, chromosome condensation, and DNA replication are down regulated, while genes related to ion transport and kinase activity are overexpressed, being markedly increased in males more than females. There are five sex-specific transcriptional regulators at 4 week (male-specific Ihh; female-specific Cdx4, Cux2, Tox, and Trim24) which may responsible for the requirement of liver sex-specificity by 8 week of age [11]. 


\section{Type 2 diabetes}

Type 2 diabetes (T2DM) is a worldwide disease, with incidence reached to 150 million people in the year 2000, and may be raised to 300 million by 2025 [12]. In Korea, it represents a major chronic disease with increased incidence reached $8.1 \%$ or 1.4 million Korean men and $7.5 \%$ or 1.3 million Korean women [13]. In Japanese people, the average of incidence reached to 13.7 to 22.1 million between 1997 and 2007 [14]. Such an increase might be attributed to an energy imbalance, feeding habit and life style accompanied with obesity.

Type 2 diabetes reflected high genetic and environmental risk factors. There is a great evidence of transmitting the disease to offspring from gestational diabetic mother [15], and attained increased rates in those of diabetic mother [16]. There is a close association between T2DM and gene-environment and gene-gene interactions and epigenetic factors such as DNA methylations and histone modifications are important mediating risk factors of T2DM [17]. Type 1 diabetic women needs higher demand of insulin in the first 2 trimesters compared to T2DM which needed more requirements in insulin per trimester especially in the late pregnancy [18]. Type 2 diabetic pregnant women possessed increased four- to ninefold increase of perinatal mortality and $6.7 \%$ of congenital abnormalities compared to type 1 diabetic pregnancies [19].

\section{Type2 diabetes and developmental origin of liver disease}

Non-alcoholic fatty liver disease (NAFLD) is the leading cause of chronic liver disease in children predicted by obesity [20] and type 2 diabetes [21]. Hepatitis affects more than a third of the population in the developmental countries [22]. The incidence of NAFLD in children is underestimated. Anderson et al. [23] reported that obese child showed highest prevalence of NAFLD reached to $7.6-34.2 \%$. The incidence of NAFLD reached to $25-50 \%$ of obese children with lifetime consequences, including liver NASH and hepatic carcinoma risk. Neonates born to obese/gestational diabetic mothers showed increased average of intrahepatic fat during 2 weeks of life [24].

NAFLD possesses hepatic steatosis assessed by accumulation of lipid within the cytoplasm of hepatocytes which progressed into steatohepatitis associated with densely grouping inflammatory cells leading to hepatic cirrhosis [25] (Figure 1). The development of the disease comes from the failure of B-cells to secrete insulin and 40 associated gene variants parallel with increased calorie intake and decreased physical activity, leading to the development of obesity [26]. Abnormal insulin secretion led to hyperglycemia, associated with altered low density lipoprotein secretion, enhanced triglyceride synthesis, impaired hepatic fatty acid oxidation and hepatic fatty accumulation [27]. Also, there is a marked increase of both nonesterified fatty acid released from the adipose tissue (lipolysis), and de novo synthesis of fatty acids (lipogenesis) [28]. Elevated hepatocellular lipids contents are also mediated by down-regulated adiponectin and/or overexpression of proinflammatory cytokines. These led to activate protein kinase $\mathrm{C}$, the transcription factor nuclear factor- $\kappa \mathrm{B}$, and c-Jun $\mathrm{N}$-terminal kinase 1 which activate the progression of hepatic steatosis, steatohepatitis and cirrhosis [29]. The incidence of NAFLD reached approximately to $70 \%$ of type 2 diabetes mellitus as a result of mitochondrial damage and increase of inflammatory pathways [30]. The prevalence of NAFLD expected to increase to $50 \%$ in the United States by $2030[31,32]$.

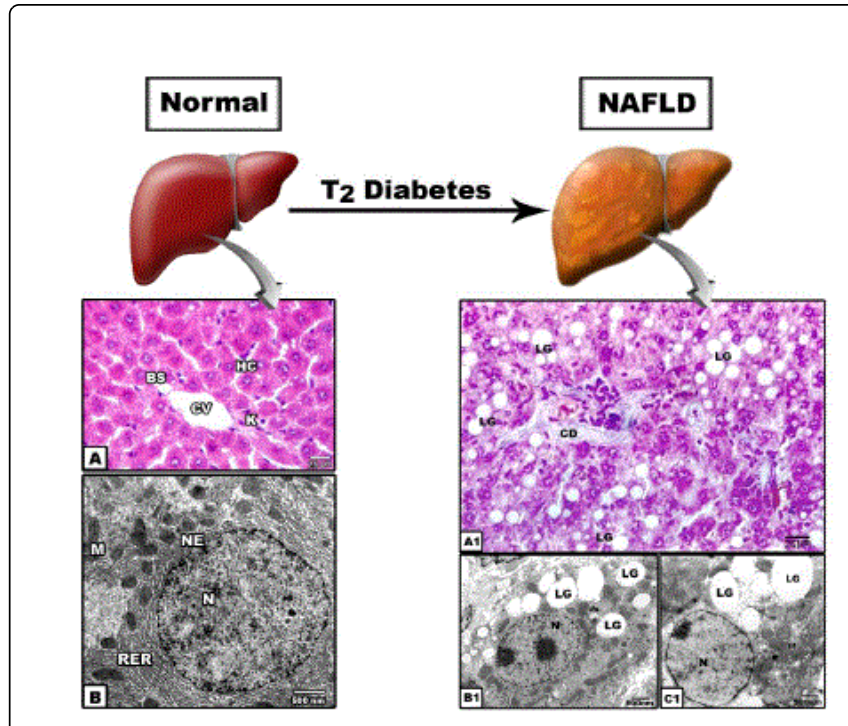

Figure 1: Histology and transmission electron microscopy of liver. A and B: Normal liver histology of hepatic cord and central blood vessel (A) and cytology of hepatocyte with central located nuclei and blood rich in rough endoplasmic reticulum and mitochondria (B). A1-C1: Type 2 diabetic liver of rats showing non-alcohol fatty liver disease with abundant lipid globules and early manifestation of collagen deposition (A1) and hepatocytes with cytoplasm rich of lipid droplets (B1\& $\mathrm{C} 1$ ). Abbreviations: BS-blood sinusoids; CV,central vein; CD-centrilobular degeneration; HC-heptocytes; KKupffer cell; LG-lipid globule; M-mitochondria; N-nucleus; NEnuclear envelope; RER-rough endoplasmic reticulum.

\section{Developmental origin of NAFLD}

The disease affects children with incidence reached to $4.2-9.6 \%$ and attributed mainly to type 2 diabetes mellitus, insulin resistance and obesity [33]. Diabetes was the most significant predictor of NAFLD following investigating of 458 Italian patients [34,35]. The NAFLD was reported in $42 \%$ patients with increased body mass index. The aspartate, alanine aminotransferase, $\gamma$-glutamyl transpeptidase, uric acid, TNF- $\alpha$, insulin and HOMA-IR were significantly higher in type 2 diabetic patients with NAFLD [36]. The levels of butyrylcholinesterase activity, $\gamma$-glutamyl transferase, cystatin $\mathrm{C}$, pre-albumin and glycemic variables were higher in the gestational diabetes mellitus patients than in the controls [37].

According to Barker et al. [1], the "developmental origins of adult disease" started early during in utero life. During which epigenetic reprogramming altered DNA transcription and gene expression into adulthood and expressed disease susceptibility. In utero life diabetic environment encourage the risk factors in the child. Studies on rodents give a close association for maternal transmission of diabetes, especially type $1 \mathrm{DM}$ and not of type $2 \mathrm{DM}$ or of gestational diabetes $(\mathrm{GDM})$, although the glucose intolerance is closely similar in the offspring. The mechanisms by which maternal type 2DM increased the average of diabetes in the offspring are result from epigenetic modification in early utero life of pathways of pancreatic $\beta$ cells, liver and muscle insulin signalling [38]. Maternal diabetes is associated with increased liver and birth weight parallel with altered liver lipid 
metabolism causing hepatic steatosis associated with obesity and metabolic syndrome in childhood [39].

Different views explained the in utero development of NAFLD. First, impairing of SIRT1 signalling in human fetal hepatocytes led to an increase in intracellular glucose and lipids levels and overexpression of genes related to de novo lipogenesis and gluconeogenesis. Second, there is a marked downregulation of AKT/FOXO1 pathway, leading to depletion of gluconeogenesis. These findings pointed out that SIRT1 represents an important promoter of lipid and carbohydrate metabolisms within the human fetal hepatocytes [40]. Also, obesity was associated with developmental programming of offspring tissues independent of high-caloric environment and more effective than malnutrition. Pancreas and liver were the most highly susceptible organs for reprogramming of the disease during perinatal life [41].

\section{Peroxisome proliferator-activated receptor- $\alpha$ (PPAR- $\alpha)$ and NAFLD}

PPAR- $\alpha$ is found in liver and other active tissues such as pancreas and promotes the genes involved in biological processes such as lipid metabolism, energy homeostasis and inflammation. PPAR- $\alpha$ is responsible for adipocyte hypertrophy and insulin resistance in high fat diet-induced obesity [42]. PPAR- $\alpha$ promoted the genes encoding enzymes responsible for the mitochondrial and peroxisomal fatty acid $\beta$-oxidation such as acyl-CoA synthetase, carnitine palmitoyl transferase I, and long-chain acyl-CoA dehydrogenase [43]. Experimental studies mentioned that PPAR- $\alpha$ is decreased by high-fat (HF) intake and consequently altered hepatic $\beta$-oxidation (mitochondrial and peroxisomal) and microsomal oxidation of lipids [44].

Overexpression of PPAR- $\gamma$, co-activator $1 \alpha$ (PGC-1 $\alpha)$, during in utero life of mice is enough to induce $\beta$-cell dysfunction in adults and consequently developed diabetes [45]. Hashimoto [46] reported that DNA methylation of the gene promoter region is a major epigenetic modification for gene expression, which can be affected by obesity and environments of type 2 diabetes. In the neonatal liver, fatty acid $\beta$ oxidation progressively increased to produce energy from the absorbed lipids. During breast feeding, DNA demethylation and overexpression of mRNA of fatty acid $\beta$-oxidation genes are processed in the liver. Maternal administration of a nuclear receptor peroxisome proliferatoractivated receptor (PPAR), a synthetic ligand; Wy14643 caused DNA demethylation of fatty acid $\beta$-oxidation-related genes in the liver of the offspring. This developed silent epigenetic memory, the activator of the PPAR- $\alpha$ gene, in the neonatal mouse liver during 10 week after birth.

Maternal obesity is contributed to hepatic fat deposition in newborn infants during in utero life and characterized by steatosis, mitochondrial dysfunction, oxidative stress, and inflammatory priming [47]. Fatty accumulation in fetal liver may come directly from the maternal lipid and represents a "first hit" of lipotoxicity during in utero life. In experimental studies, maternal intake of high fat diet increased neonates de novo lipogenesis and more progressed in early adulthood due to the increased expression of hepatic transcription factor sterol regulatory element binding protein $1 \mathrm{c}$ (SREBP1c) and downstream of lipogenic targets: peroxisome proliferator-activated receptors, fatty acid synthase, stearoyl-CoA desaturase-1, and acetylCoA carboxylase [48] (Figure 2). About of $23.3 \%$ of the obese Taiwanese children possessed NAFLD and expressed the PPARGC1A rs8192678 risk A allele [49]. The protein PGC-1a, encoded by the PPARGC1A gene, manages mitochondrial biogenesis and function, oxidative stress, gluconeogenesis, and lipogenesis, which are key factors for inducing NAFLD [50].

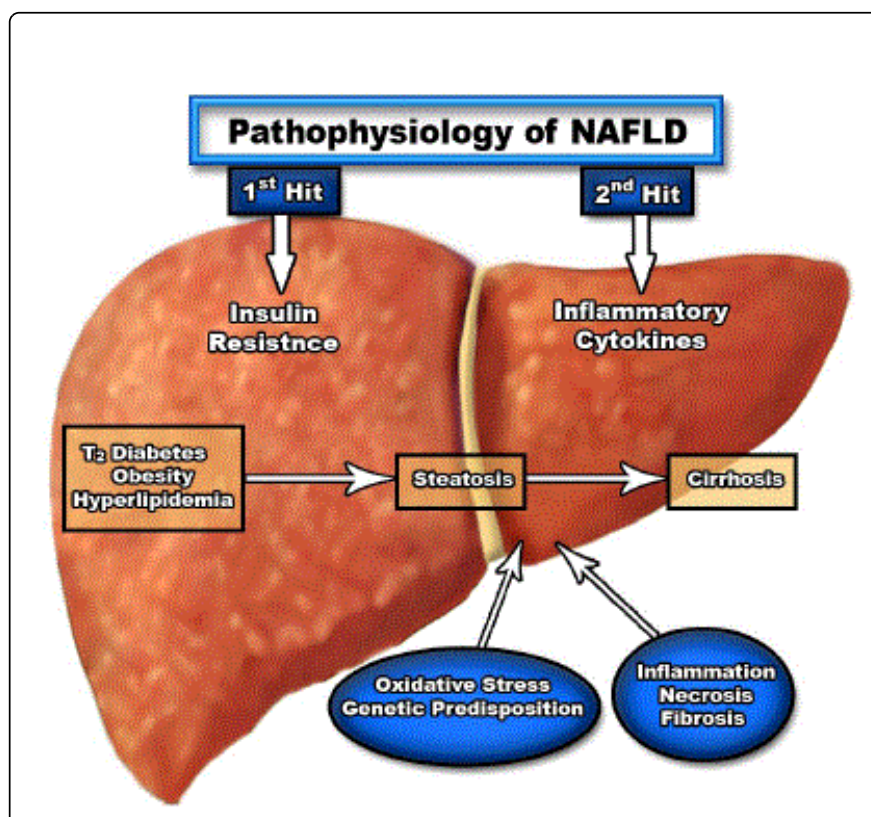

Figure 2: Pathophysiology of non-alcoholic fatty liver disease (NAFLD). Two models illustrated the pathogenesis "Ist Hit" \& 2nd Hit". Different factors are involved in the development of NAFLD are illustrated by white arrows [48].

Fetuses of mother rat fed on diet rich in $3 \%$ cholesterol possessed lipid loaded hepatocytes coincides with vesicuolated rough endoplasmic reticulum, abnormal electron dense mitochondria and increased average of apoptic hepatocytes and over expression of caspases 3 and 9 [25].

\section{Type 2 diabetes and obesity related NAFLD}

Obese offspring may come from transmission of programmed phenotypes through the maternal lineages during in utero life. Excessive weight gain and/or maternal obesity are the more risk factors. This led to a sequence of obesity and diabetes in successive generations. Early childhood obesity predicted the onset of nonalcoholic fatty liver disease. The fetus may be susceptible to steatosis due to missing of immature fetal adipose depots, the buffer of transplacental lipid delivery. In non-human primates, maternal obesity and a high fat diet [51,52] as well as diet rich in cholesterol [25] during gestation increased the oxidative stress, apoptosis, accumulation of liver lipid associated with necroinflammatory changes. Diabetes is associated with altered lipid metabolism and increase cholesterol, LDL and triglycerides which intern developed similar NAFLD parallel with cytolysis of B cells [25,53]. The hepatocyte nuclear factor (HNF) promotes the gene family involved in lipid, carbohydrate, and protein metabolism. Mutation of humans HNF1A predicted the onset of diabetes in the young, whereas murine HNF6 participates in fetal liver B lymphopoiesis associated with altering of innate immunity [54]. In animal models, impairing of innate immune and increased inflammatory changes has been reported in liver of neonates maternally fed on high-fat-diet similar to human NAFLD [52]. 
According to the speculation of Ugalde-Nicalo and Schwimmer [55], the diagnosis of non-alcoholic fatty liver disease (NAFLD) in 12 years-old raised many questions about its origin "when did this begin?" There is increasing evidences that NAFLD makes their first appearance at birth or even in utero. Neonatal hepatic steatosis was reported in those of obese-related gestational diabetes [56] or diabetic women [57]. Maternal obesity led to abnormal feto-placental development under stress conditions of both excess nutrients and inflammation. During first and second trimester, overload of fetal lipid exposure, may impair the liver function and other developing organs, leading to insulin resistance and susceptibility to fatty liver throughout life. This led to increased hepatic steatosis as a result of de novo lipogenesis, fatty acid oxidation and lipoprotein export [55]. Maternal high fat diet retarded fetal expansion of hemopoietic stem progenitor cells coincide with impairing genes regulating metabolism, immune and inflammatory processes [58].

Environmental and genetic factors are involved in the development and progression of NAFLD but its physiopathology is not yet clearly detected. Obese pregnant women may carry their metabolic phenotype to their offspring, leading to obesity and diabetes in successive generations as well as predicts nonalcoholic fatty liver disease [52]. Many factors are involved in the development of the disease. Day [59] proposed two hypotheses. The first involved that hyperinsulinemia and insulin resistance, accompanying obesity, led to fat accumulation in hepatocytes, liver steatosis and increased lipid peroxidation. Also, there is a marked overexpression of free-fatty-acids uptake in the liver, increased triglycerides synthesis, decrease of apolipoprotein B-100, and increase $\beta$-oxidation of mitochondrial long-chain fatty acids. The second hypothethesis explained by the release of reactive oxygen species (ROS) which accelerate hepatocellular injury via decreasing the activities of the mitochondrial respiratory chain enzymes and glyceraldehyde-3-phosphate dehydrogenase and impairing of membrane sodium channels. Lipid peroxidation, cytokine production, and Fas Ligand, are contributed to hepatocellular injury and fibrosis during the progression of NAFLD to NASH [60]. The gestational environment transfer high metabolic nutrients to the fetus facilitated hepatic fat accumulation illustrating in utero epigenetic changes. The liver is a primed for postnatal fat storage and inflammation mediated by Kupffer cells [52]. In animal models, in utero high-fat diet and/or diabetes resulted in an increase in circulating maternal triglycerides and fatty accumulation in hepatocytes of mothers and their offspring leading to apoptosis and development of subsequent NAFLD [25]. Transmission of microbiota from mother to infant may represent a new hypothesis of impact energy retention and immune function that contribute to the development of NAFLD [52].

\section{Role of pancreatic islets in NAFLD}

Pancreatic islets are highly organized micro-organs with a distinctive arrangement of endocrine cells. Abnormal secretions of glucagon and insulin are contributed to type 1 and type 2 diabetes. The islets are highly innervated by adrenergic sympathetic nerves originating from the celiac and superior mesenteric ganglia [61]. The sympathetic neural activity is well-known to inhibit insulin secretion and promote glucagon release to evoke an increase in circulating glucose during stress and exercise [62]. Non-human primates (NHP) exposed to maternal high-fat diet (HFD) showed reduced sympathetic innervations of the liver, causing hypothalamic inflammation which may impair pancreatic islet cell function [63]. Genetic or pharmacological ablation of sympathetic innervations led to altered islet structure, reduced insulin secretion and impaired glucose tolerance in mice [64].

Lifestyle, with increasing caloric food intake and reduced physical activity, has resulted in progress of obesity-related type 2 diabetes (T2D). In insulin-resistant states, $\beta$ cell compensation occurred as a result of expansion of the $\beta$ cell mass may cause increase in insulin secretion to normalize blood sugar level [65]. Increased $\beta$ cell mass has been observed in the pancreas of obese compared with lean nondiabetic subjects [66]. In the obese, the relative (to the exocrine tissue) B-cell volume (which averaged $2 \%$ of whole pancreatic volume) was increased by $50 \%$ in comparison with the lean. There are different factors involved in the regulation of obesity-driven $\beta$-cell proliferation, including nutrients, insulin, incretins, hepatocyte growth factor, and recently identified liver-derived secreted factors [67]. The obesity caused proliferative expansion of $\beta$-cells parallel with increased body weight gain and degree of insulin resistance in high-fat-diet models [68]. Hyperinsulinemia in HF fed mice was associated with increased both islet mass and size correlated with higher BrdU incorporation to $\beta$-cells and increased oxygen intake [69].

The inflammatory environment in the obese adipose tissue and pancreatic $\beta$-cell islets creates imbalance and overexpression of inflammatory macrophage leading to insulin resistance in the adipose tissue and pancreatic $\beta$-cell dysfunction [70,71]. There is a close association between obesity and type 2 diabetes resulted from decreased insulin secretion parallel with increased insulin resistance [72]. Obesity and overweight in children may be due to the epidemic of NAFLD [73].

\section{Role of cytoplasmic organelles}

Endoplasmic reticulum: Disturbance in endoplasmic reticulum (ER) homeostasis has been contributed to both steatosis and the progression to NASH [74]. The ER stress led to de novo lipogenesis, mitochondrial dysfunction, oxidative stress, inflammation, and cell death [75]. High fat diet, activated ER stress markers (binding of immunoglobulin protein), C/EBP homologous protein, ER-associated oxidoreductin 1- $\alpha$, and eukaryotic translation initiation factor $2 \mathrm{a}$ (eIF2a) [76]. Glycosyltransferases (GTs) are a set of enzymes catalyzing the transfer of one or multiple sugar residues to lipids, proteins, hormones, secondary metabolites, and oligosaccharides $[77,78]$ and mediate the storage function [79]. They are synthesized and transported from the ER to the Golgi via COPII-transport vesicles [80]. Impairing insulin signaling pathway have been reported in obese patients, involving complex interactions of elevated inflammatory mediators, adipokines, and endoplasmic reticulum (ER) stressdependent unfolded protein response (UPR) [81]. There is a detected change of ER stress signaling such as ATF6, GRP78, CHOP and caspase12 in the liver tissues during early stage of steatohepatitis of diabetic mice [82] (Figure 3).

Lysosomes: Autophagy is a phenomenon through which lysosomes phagocytosed and degraded damaged organelles, and intracellular pathogens and recycling of intracellular organelles to manage cellular homeostasis under various stresses such as oxidative stress, and endoplasmic reticulum (ER) stress [83]. In vitro exposure of hepatocytes to excess free fatty acids led to Bax translocation (proapoptic protein) to lysosomes and consequently led to release of cathepsin B, a lysosomal cysteine protease, into the cytosol. Release of cathepsin into the cytoplasm was also observed in humans with NAFLD [84]. Also, exposure of mouse hepatocytes, HepG2 and McNtcp cells to high free fatty acid resulted in mitochondrial 
depolarization, cytochrome c liberation, and increased ROS production prior to mitochondrial damage [85]. Lipids derived from circulating fatty acids released by insulin resistance (IR)-impaired peripheral lipolysis. Fatty acids are taken up into the hepatocytes by membrane-bound transporters [86]. De novo lipogenesis leads to hepatic steatosis, steatohepatitis and hepatic fibrogenesis $[28,87]$. Autophagy is also involved in maintaining homeostatic balance of energy metabolism and cellular organelle and protein turnover, and tissue remodeling, a process controlled by small non-coding microRNAs that promote gene expression [88]. Dysregulation of microRNAs altered both physiological and pathological conditions [13].

There is a causal link between lysosomal cholesterol accumulation and inflammation [89] and development of atherosclerosis and NASH [90] (Figure 3).

Mitochondria: Aged and damaged mitochondria are removed from cell by autophagy process to prevent the release of pro-apoptotic proteins from mitochondria, ROS generation, and ATP depletion [91]. Miwa et al. [92] reported that its half-life was approximately 2 days. Hyperglycemia altered mitochondrial function through reducing oxidative phosphorylation, and producing of ultra-structural abnormalities [93]. Hepatocytes of NAFLD possessed mega mitochondria, intra-mitochondrial crystalline inclusions, mitochondrial matrix granules, foamy cytoplasm and glycogencontaining nuclear regions, lipofuscin granules, or an increased number of vesicles having electron-dense material in peribiliary Golgi zone [94].

Oxidative stress and impaired antioxidant defense play a great role in the pathogenesis of steatosis, steatohepatitis, and fibrosis. These were carried out by impairing of mitochondrial function and increase of free fatty acid metabolism parallel with liberation of free oxygen species which increased myeloperoxidase activity and accumulation of oxidized low density lipoprotein. These led to the development hepatitis characterized by triglyceride accumulation, apoptosis, inflammation, stellate cell activation, and fibrogenesis [95]. Liver of obese diabetic patients revealed alterations of mitochondrial function and methionine metabolism (the biproduct of glutathione), via the trans-sulfuration pathway, and abnormal levels of protein and lipid oxidative damage which may be affected the development of NAFLD [96].

Kupffer cells also, play a great role in the development of pediatric NASH. Ultrastructural studies revealed that the presence of numerous hypertrophied Kupffer cells with increased phagocytic activity along the hepatic sinusoids, which reduced or obstruct vascular lumen. Hypertrophied Kupffer cells exhibited primary and secondary lysosomes, altered mitochondria, and well-developed Golgi apparatus. It is aligned close to the transformed hepatic stellate cells and progenitor/oval cells. Fibrosis was observed in activated Kupffer cells/MPs in the form cytoplasmic bundles of collagen fibers [97]. Although non-alcoholic steatohepatitis is benign and reversible, inflammation may increase liver damage. Hepatic inflammation induced abnormal accumulation of $27-$ Hydroxycholesterol $(27 \mathrm{HC})$ in lysosomes of Kupffer cells attributed to CYP27A1, the cause of mobilizing it to the cytoplasm [98] (Figure 3).

Golgi complex: Increased de novo lipogenesis, is detected in NAFLD and insulin resistance. Sterol regulatory element-binding protein 1 (SREBP1), is synthesized in an inactive form in the endoplasmic reticulum. It is come from the endoplasmic reticulum to the Golgi in a COPII-dependent manner, processed by proteases in the Golgi, and then transferred to the nucleus to express lipogenic gene. During feeding, mTOR phosphorylates CRTC2 and attenuates its

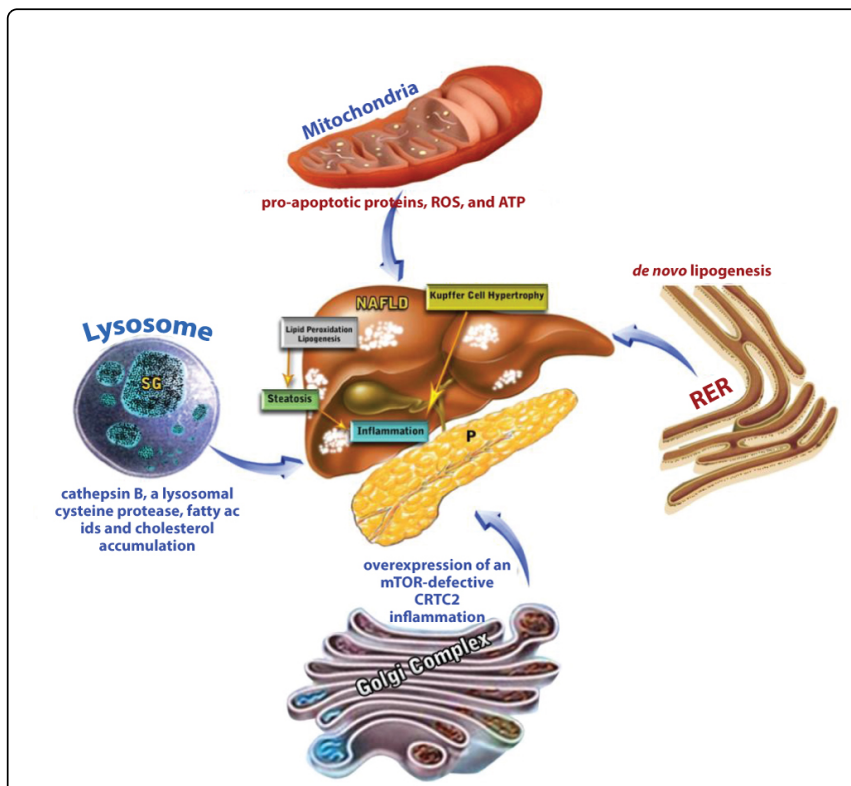

Figure 3: Diagrammatic representation the origin of non-alcohol fatty liver disease and role of mitochondria, lysosomes, rough endoplasmic reticulum and Golgi complex in its development; P, pancreas; RER, rough endoplasmic reticulum; SG, secretory granules.

Inhibitory effect on COPII-dependent SREBP1 maturation. Overexpression of hepatic mTOR-defective CRTC2 mutant in obese mice improved the lipogenicity and insulin sensitivity [99]. Inflammation increased lipid accumulation in hepatoblastema (HepG2) cells and in livers of apolipoprotein E knockout mice, parallel with an increase in low density lipoprotein receptor (LDLR) gene transcription, overexpression of sterol regulatory element-binding protein (SREBP) and increased translocation of the SCAP/SREBP-2 complex from endoplasmic reticulum (ER) to Golgi [100] (Figure 3).

\section{Management of non-alcohol fatty liver disease}

The mean strategy to overcome NAFLD in type 2 diabetes is to reduce the obese weight through lifestyle modification via calorierestricted diet and increased physical activity [101].

\section{Pharmacologic therapy}

\section{Metformin}

It is a biguanide drug that is widely used for treating type 2 diabetes. It inhibits hepatic gluconeogenesis and increases fatty acid oxidation. Also, metformin acts, via activation of the liver kinase B1 (LKB1)/ AMP-activated protein kinase (AMPK) pathway, the molecular mechanism regulating glucose and lipid metabolism. Inositol polyphosphate multikinase (IPMK) plays a great role in cellular energy metabolism and glucose-mediated AMP-activated protein kinase regulation (AMPK). Overexpression of wild-type IPMK was sufficient to restore LKB1-AMPK activation by metformin [102]. In the liver, 
AMPK reduces hepatic gluconeogenesis via the activation of the phosphorylation of CREB-binding protein (CBP) and breakdown of the gluconeogenic CREB-CBP-TORC2 transcriptional complex [102]. Metformin-induced phosphorylation, AMPK inactivated acetyl-CoA carboxylase (ACC) and 3-hydroxy-3-methylglutaryl (HMG)-CoA reductase, decreased fatty acid synthase (FAS) expression, and activated malonyl-CoA carboxylase. All these $\mathrm{co}=$ operated for depletion of fatty acid and cholesterol synthesis [103].

It is known that overexpression of adiponectin, induced by metformin, directly stimulates AMPK and prevents hepatic lipid accumulation by increasing $\beta$-oxidation of free fatty acids and/or by decreasing their de novo synthesis. Experimental studies in ob/ob mice, a model of hepatic steatosis, revealed that metformin reversed hepatomegaly, hepatic fat accumulation, and transaminases abnormalities, by decreasing hepatic tumor necrosis factor- $\alpha$ (TNF- $\alpha$ ) expression [104].

Although, AMPK is the main factor promoting metformin activities, and is mediated by MAPK- and PKA-dependent mechanisms and consequently impairing. Catecholamine-stimulated lipolysis [82].

In mice fed on high fat diet, metformin- treatment decreased hepatic steatosis and inflammation and increased phosphorylation of AMP-activated protein kinase (AMPK). However, in the in vitro systems, metformin act directly on hepatocyte and macrophage inflammatory responses and improving adipose phenotype [104]. Weight reduction achieved by diet and exercise is effective in prevention and treatment of NAFLD in obese diabetic subjects. The combination of rosiglitazone to metformin in a 24 -week randomized, significantly decreased $\mathrm{HbAlc}$ level and improved insulin sensitivity and HOMA $B$ cell function [105]. Dapagliflozin, a highly selective inhibitor of SGLT2, showed a great efficacy, alone or in combination with metformin, in reducing hyperglycemia in patients with type 2 diabetes [106]. Saxagliptin at doses of $2.5,5$, and $10 \mathrm{mg}$ plus metformin decreased $\mathrm{HbAlc}$ by $0.59 \%, 0.69 \%$, and $0.58 \%$, respectively, in comparison to an increase in the metformin plus placebo group [107].

Exercise exhibited amelioration of diabetes and NAFLD in obese hyperphagic OLETF rats compared to metformin alone [108].

\section{Thiazolidinediones}

Thiazolidinediones (TZDs) are anti-diabetic agents act mainly in increasing insulin sensitivity and agonist PPAR- $\gamma$ drugs. Three TZDs have been FDA-approved for diabetes: troglitazone (Rezulin), rosiglitazone (Avandia), and pioglitazone (Actos) [109]. Some studies attributed hepatotoxicity to the reactive metabolites of troglitazone [110], while others indicated that troglitazone activates the pregnane $\mathrm{X}$ receptor in humans but not the rodents [111]. The TZDs improve metabolism in patients with type 2 diabetes through activation of the $\gamma$ isoform of the peroxisome proliferator-activated receptor (PPAR- $\gamma$ ). The drug altered the transcription of several genes involved in glucose and lipid metabolism and energy balance, including those that promote lipoprotein lipase, fatty acid transporter protein, adipocyte fatty acid binding protein, fatty acyl-CoA synthase, malic enzyme, glucokinase and the GLUT4 glucose transporter [112].

Thiazolidinediones are active ant diabetic agents via increasing insulin sensitivity and consequently improve NAFLD through reduce hepatic fatty acid accumulation [113]. Treatment 60 T2DM patients complicated with NAFLD for 12 weeks with piglitazone and/or metformin led to decrease of body mass index, fast blood glucose, insulin resistance, glucose hemoglobin A1C, fasting insulin, and triglycerides. Piglitazone is more effective than metformin in decreasing retinol-binding protein-4 level and insulin resistance in patients with T2DM complicated with NAFLD [114]. Cytochrome P450 2E1 catalytic activity was increased in experimentally induced non-alcoholic steatohepatitis and improved post-treatment with pioglitazone [115]. Metformin-treatment in combination with gliclazide, pioglitazone, sitagliptin, exenatide, or liraglutide drugs led to improvements of NAFLD in diabetic patients [116].

Follow up thirty patients with NAFLD and treated with rosiglitazone ( $8 \mathrm{mg}$ daily for 48 weeks) revealed improvement in 13 and worsened in one; fibrosis score improved in 8 and worsened in 3 [117]. The patients received either $4 \mathrm{mg}$ twice-daily of rosiglitazone, 4 $\mathrm{mg}$ of rosiglitazone and $500 \mathrm{mg}$ of metformin twice-daily, or $4 \mathrm{mg}$ of rosiglitazone twice-daily and $50 \mathrm{mg}$ of losartan once-daily for 48 weeks showed increased amelioration in steatosis, hepatocellular inflammation, ballooning degeneration, and fibrosis [118].

A 48 week trial of pioglitazone (30 mg daily), in 18 patients [119] showed improved of transaminases. Six months treatment possessed reduction of fibrosis by $61 \%$ [120]. Ratziu et al. [117] compared diet plus pioglitazone to diet plus placebo in 55 patients and observed significant amelioration in ALT (by 58\%), hepatic fat content (by 54\%) and insulin sensitivity (by 48\%) coincides with amelioration of histologic picture.

\section{Statins}

Statins (hydroxy-methyl-glutaryl coenzyme A (HMG CoA) reductase inhibitors) are widely used antilipidemic drugs. Two aspects are important regarding statins treatment in NAFLD. First, its therapeutic benefit and safe without altering liver function tests. Second, its therapeutic potential of NAFLD in absence of dyslipidemia taking in consideration the close association between NAFLD and metabolic syndromes, such as obesity and insulin resistance [121].

Atorvastatin improved liver function in 44 obese adults with NASH, including 10 patients with diabetes [122]. Pravastatin-treatment $(20$ mg daily for 6 months) improved hepatic inflammation. Treatment 23 hyperlipidemic patients with rosuvastatin managed transaminases and low density lipoprotein as well as histopathological pictures [123]. From available works, statin therapy, at low-to-moderate doses, seemed to be safe and had low liver toxicity. The improvement of NAFLD post-statins therapy comes from decreased levels of tumor necrosis factor- $\alpha$, interleukin- 6 , and possibly C-reactive protein $[124,125]$, reduced liver free fatty acids [126], and altered adiponectin metabolism [127]. Although there is no ideal pharmacotherapy for NAFLD, recent therapeutic strategies have focused on the indirect upregulation of adiponectin through the administration of statin which ameliorate liver structure [128].

\section{Fenofibrate}

Fenofibrate is a class of drugs with chemical formula "propan-2-yl 2-\{4-[(4-chlorophenyl) carbonyl] phenoxy\}-2-methylpropanoate". The drug-treatment alone or in combination with statins alleviated TG and raising HDL-C levels [129]. The drug shows anti-inflammatory, antithrombotic actions, and improving the endothelial function, particularly in patients with metabolic syndrome (MetS) and T2DM [130]. 
Fenofibrate was found to deplete hepatic triglycerides accumulation in high fat diet [131], reversed the development of hepatic steatosis, necroinflammation and collagen deposition [132]. The drug activated PPAR- $\alpha$ which enhanced hepatic fatty acid turnover, fatty acid transport protein, fatty acid binding protein, carnitine palmitoyltransferase II, as well as medium- and long-chain acyl-CoA dehydrogenase and acyl-CoA oxidase [133].

In humans, fenofibrate is more effective in treatment of NAFLD comparing with the others drugs. It has insulin-sensitizing action and showed a significant amelioration in hepatic transaminases coupled with a marked decrease of hepatocellular ballooning in humans. The mechanism of antilipedimic action of fenofibrate, is come from activating PPAR- $\alpha$, and effectively improves the atherogenic lipid profile associated with T2DM. This is carried out through enhancement the expression of genes promoting hepatic FA $\beta$ oxidation, reduction of inflammatory mediators, tumor necrosis factor- $\alpha$, intercellular cell adhesion molecule-1, vascular cell adhesion molecule-1 and monocyte chemoattractant protein-1 [134].

Pan-PPAR activation by bezafibrate triggered beneficial effects in offspring from obese dams derived from PPAR- $\alpha$ activation (increased CPT-1 expression in the liver) [135].

\section{Antioxidants \& NAFLD}

It is known that NAFLD is associated with the activation of the immune system, aggregation of lymphocytes within sinusoidal vein and portal tract, overexpression of inducible nitric oxide synthase (iNOS), and infiltration of polymorphonuclear leukocytes (PMN) [136]. The oxidative stress is the main etiological factor of the disease [137]. Vernon et al. [138] reported hepatocyte damage and progression of liver fibrosis by lipid peroxidation, inflammation and mitochondrial dysfunction in NAFLD. Antioxidants actively antagonized oxidative stress and prevent or delay the oxidation of substrates, such as lipids, proteins, DNA, DNA mutations, and other cell damage [139]. It is known that mitochondria is the major site of ROS such superoxide, hydrogen peroxide, hypochlorite, hydroxyl radical, nitric oxide, and peroxynitrite. Other cell organoids like plasma membrane systems, endoplasmic reticulum, lysosomes, peroxisomes and cytosolic enzymes are also involved [140]. Recent evidences mentioned that the oxidative stress may be the mechanistic link between obesity and related complications. Obese individuals may have a lower intake of antioxidant- and phytochemical-rich foods, beside the inadequate physical activity may account for a decreased antioxidant state [141].

Mitochondrial dysfunction, ER stress, and hyperglycemia seemed to be involved in the development of NAFLD. Hepatic steatosis is associated with the increase of carnitine palmitoyltransferase-1 (CPT1A) activity causing high fatty acid levels. The disease associated with altered mitochondrial structure and function and liberation of ROS [142]. Also, the by-products of lipid peroxidation generate 4HNE-CPT1 adducts, and inactivation CPT1 facilitated free fatty acids accumulate. ER stress triggers apoptosis via calcium alterations, ROS release and activation of JNK-dependent signals causing pro-apoptotic pathways [143].

\section{Role of phytobioactive compounds}

Glycyrrhizin: Glycyrrhizin (GL) is the main bioactive component of licorice root extract with higher anti-inflammatory, antioxidant, and immune-modulating activities. It is composed mainly of glycyrrhetinic acid, _-sitosterol, flavonoids, and hydroxycoumarins [144]. Eighteen
B-glycyrrhetinic acid (GA), is the biologically active metabolite of GL, prevented FFA-induced lipid accumulation and cell apoptosis in vitro HepG2 (human liver cell line) NAFLD models. GA stabilized lysosomal membranes, inhibit cathepsin $\mathrm{B}$ expression and enzyme activity, inhibit mitochondrial cytochrome $\mathrm{c}$ release, and reduce FFAinduced oxidative stress [145].

NAFLD patients received $2 \mathrm{~g}$ aqueous licorice root extract per day for 2 months liver enzymes and had increased liver echogenicity (lipid accumulation) [146]. Intraperitoneal administration of a single dose of glycyrrhizin $((50 \mathrm{mg} / \mathrm{kg}$ body weight $)$ to rat previously fed on a fructose-enriched diet (60\%) for 6 weeks manage blood sugar level, insulin, lipid and antioxidant enzymes as well as decreased the levels of perioxosome proliferator activated receptor- $\gamma$ and glucose transporter 4 [147].

Gynostemma pentaphyllum: Gynostemma pentaphyllum (GP) (Southern Ginseng) is a dioecious, herbaceous climbing vine distributed in Eastern Asian and given ginseng status. Gynostemma pentaphyllum tea is used to treat type 2 diabetic patients [148] and experimental rat [149].

It is able to protect hepatocytes from cell death, lipid accumulation, and oxidative stress caused by diabetic-like metabolism via stimulates the production of nitric oxide in hepatocytes which alters the molecular composition of the mitochondrial phospholipid cardiolipin. Also, GP- treatment markedly decrease serum AST, ALP, insulin, and decrease the body mass index (BMI) and insulin resistance index [150]. Ombuin is a flavonoid isolated from GP showed a decrease of intracellular concentrations of triglyceride and cholesterol in liver cancer cells as well as reduce the expression of some biogenic genes through activating PPAR- $\alpha$ and $\beta / \gamma[151]$.

Quercetin: Apples, onions, teas, red wine, berries, seeds, leafy green vegetables, hot peppers, parsley and red grapes contain rich amounts of quercetin. These plants are rich in polyphenolic flavonoids which exerted antioxidant and anti-inflammatory effects through its inhibitory function of the lipoxygenase and cyclooxygenase pathways [152].

In vitro studies of quercetin at concentrations of 0.1 and $100 \mu \mathrm{M}$ increased tyrosine phosphorylation and decreased the levels of the sterol regulatory element-binding protein-1c (SREBP-1c) and fatty acid synthase (FAS) which ameliorated insulin resistance and hepatic lipid accumulation [153]. In vivo studies of quercetin $(75 \mathrm{mg} / \mathrm{kg} /$ day vs. 300 $\mathrm{mg} / \mathrm{kg} /$ day) to NAFLD rat model fed on high fat diet for 4 weeks revealed significant decreases in the liver index, FBG and IL-18 (all, P less than 0.01), and significant increase in IL-10 [154].

Rats fed in high fat diet and received quercetin $(\mathrm{Q})$, berberine (BB) and o-coumaric acid (CA) improved serum and hepatic dyslipidemia, alterations in metabolic enzyme activities (lipase, glycerol-3-phosphate dehydrogenase, and glucose-6-phosphate dehydrogenase), micro- and macrovesicular hepatic steatosis and the down regulation of peroxisome proliferator-activated receptor $\gamma($ PPAR- $\gamma)$ [155].

Five-week-old ob/ob mice fed on a diet containing $0.08 \%$ quercetin exhibited improvement of dyslipidemia, insulin homeostasis, liver enzymes, and decreased tumor necrosis factor and overexpression adiponectin which protect against NAFLD [156]. Quercetin-treatment has a great advantage of reducing AKT phosphorylation, and oxidative/nitrosative stress, inflammation and lipid metabolism-related genes which displayed affinity to normalize in both in vivo and in vitro models [157]. 
Other phytochemical plants such as Morus alba leaves extracts [158], black rice extract [159], barley beta-glucan [160], pomegranate juice and peel $[161,162]$, nuts rich in omega-3 fatty acids [163], resveratrol [164,165], green tea polyphenol Epigallocatechin-3-gallate [166], Fenugreek, Nigella, and termis seeds [167], Artemisia scoparia extract [168] and onion [169].

Astaxanthin: Carotenoids are vitamin A derivates like $\beta$-carotene, astaxanthin, lycopene and retinol, which are of antioxidant power. Carotenoids is obtained from natural sources such as orange-coloured fruits and vegetables like carrots, apricots, mangoes, squash, spinach, kale, collard greens, guava, and grapefruit. Astaxanthin (3, 3'dihydroxy- $\beta$-carotene- $4,4^{\prime}$-dione) is a keto-carotenoid, belongs to terpenes from the same family as lycopene, lutein, and $\beta$-carotene, synthesized de novo by some microalgae, plants, yeast and bacteria such as Haematococcus pluvialis $[170,171]$. It is derived from Bcarotene by 3-hydroxilation and 4-ketolation by B-carotene hydroxylase and B-carotene ketolase, respectively [172]. The antioxidant activity astaxanthin is 65 times than vitamin $C, 54$ times stronger than $\beta$-carotene, 10 times more potent than $\beta$-carotene, canthaxantin, zeaxanthin, and lutein; and 100 - to 500 -fold greater than a-tocopherol [173-176].

Astaxanthin showed a proper antilipedimemic activity via decreasing low density lipoprotein (LDL) - cholesterol the marker of cardiovascular disease in patients $[177,178]$ as well as in obese mice fed a HFD [179]. Obese mice fed on high fat diet and received astaxanthin-treatment alleviated the increase of plasma alanine transaminases (ALT) and aspartate transaminases (AST). The endogenous antioxidant mechanism assessed by overexpression of hepatic mRNA of nuclear factor erythroid 2-related factor 2 and its downstream genes was reported post- astaxanthin-treatment [180].

Astaxanthin-treated mice previously fed on a high-cholesterol and high-fat diet showed improved excessive hepatic lipid accumulation and peroxidation coincides with altered macrophages/Kupffer cells and a depletion in CD4 (+) and CD8 (+) T cell overexpression in the liver, which alleviated insulin resistance and hepatic inflammation. This led to improve hepatic steatosis and ameliorated the progression of NASH in biopsy-proven human subjects [181].

Astaxanthin treatment impaired triglyceride accumulation and liver steatosis by inhibiting PPAR- $\gamma$ present in transcription factor YY1 induced zebrafish liver steatosis [182] hypercholesterolemic diet fed Guinea pigs fed on high fat diet containing cholesterol showed hepatic free cholesterol, hepatic MDA and TNF- $\alpha$ which were decreased in the lutein supplemented group, the promising of NAFLD [183].Also, astaxanthin improved NAFLD via managing macrophage polarization and liver homeostasis [184].

In vitro studies in LX-2 cells (haematopoietic stem cells), astaxanthin-treatment reduced liberation of reactive oxygen species as well as decreased tumor growth factor $\beta 1$ - which activate overexpression of $\alpha$-smooth muscle actin ( $\alpha$-SMA) and procollagen type 1 , alpha 1 (Col1A1) mRNA and a-SMA protein levels, the markers of liver fibrosis [180].

\section{Gene therapy}

NAFLD is a complex disease that occurs when environmental factors act upon a susceptible polygenic background composed of multiple independent modifiers. The detection of PNPLA3 as a modifier of disease outcome during development of NAFLD from steatosis to fibrosis and hepatocellular carcinoma; and the discovery of
TM6SF2 as a "master regulator" of metabolic syndrome development, determining not only risk of liver disease, but also cardiovascular disease outcomes [185].

Genetic modifiers of NAFLD have been identified via genome-wide association studies. These include the Patatin-like phosholipase domain-containing 3 (PNPLA3) gene variant I148M as a predictor of inter-individual and ethnicity-related differences in hepatic fat content independent of insulin resistance and serum lipid concentration. The I148M polymorphism is also a strong modifier of NAFLD. Also, there is a role for genetic variants implicated in insulin signalling, oxidative stress, and fibrogenesis of NAFLD are key operative mechanisms closely involved in the progression of liver damage. It is now important to clarify the molecular mechanisms underlying these associations between gene variants and progressive liver disease, and to evaluate their impact on the response to explore novel therapeutic targets and could guide physicians towards improves clinical outcome [186].

Gene therapy represents the recent topic of treating this disease. Long-term hepatic SIRT1 overexpression led to up regulation of key hepatic genes participated in $\beta$-oxidation, impaired high carbohydrate diet-involved in lipid accumulation and decreased liver inflammation. AAV8-Sirt1-treated mice improved insulin sensitivity, increased oxidative capacity in skeletal muscle and reduced white adipose tissue inflammation [187].

Adiponectin-encoding gene (ADIPOQ) detected on chromosome $3 q 27$, computing adiponectin protein which is an adipocyte-derived hormone with anti-atherogenic, anti-diabetic and anti-inflammatory properties via attenuates insulin resistance by increasing its sensitivity. Adiponectin rs266729 $(-11377 \mathrm{C} / \mathrm{G})$ polymorphism might be a candidate gene, which marked the prediction of NAFLD [188]. A study in Indian patients showed an association of two functional polymorphisms, rs266729 and rs2241766 (+45 T/G) of ADIPOQ with NAFLD, the presence of $G$ allele at position -11377 correlated with necro-inflammatory grade and at position +45 resulted in reduced plasma adiponectin levels in patients clarifying the role of these polymorphisms in development of NAFLD [189].

Leptin receptor gene (LEPR) is encoded on the chromosome $1 \mathrm{p} 31$ and promotes the work of leptin. The polymorphism of LEPR 3057G > A (rs1805096) may responsible to the onset of NAFLD by regulating lipid metabolism and altering insulin sensitivity [190]. LEPR rs1137100 is associated with increased risk of NAFLD and NASH [191].

RNA interference has recently observed as an innovative tool for gene silencing that degrades mRNAs complementary to the antisense strands of double-stranded, short interfering RNAs (siRNAs). It has a great therapeutic potential over small-molecule drugs due to targeting all genes and allows selective silencing of one or several genes [192].

Peroxisome proliferator-activated receptors are classified into three types, each of which encoded by a different gene: PPAR (NR1C1), PPAR (NR1C3), and PPAR (NP1C2). Carriers of the PPAR- $\gamma$ Ala allele possessed increased resistance to the development and progression of NAFLD by antagonizing oxidative stress [193]. A Meta-analysis reported a protective role for the Ala allele of the PPAR- $\gamma$ Pro12Ala (rs1801282) polymorphism in NAFLD [51], and rs1801282 polymorphism is associated with susceptibility to NAFLD in East Asians, but not in European populations [194]. Rats fed on high fat diet containing $1 \%$ cholesterol and supplemented açai pulp ( 2 g/day) for 6 weeks exhibited overexpression of serum paraoxonase isoform 1 
activity which was parallel with a reduction in hepatic steatosis and hepatic injury [195].

PLA2G6 or GVIA calcium-independent PLA2 (iPLA2 $\beta$ ) is one of the NAFLD modifier genes in humans, important for targeting NAFLD therapy. It is responsible for phospholipid metabolism and remodeling. iPLA2 $\beta$ might regulate obesity and hepatic steatosis in leptin-deficient mice by cross-breeding $\mathrm{PKO}$ with $\mathrm{ob} / \mathrm{ob}$ mice to generate ob/ob-PKO mice. This leads to significant reduction in serum enzymes, lipids, glucose, insulin, improved glucose tolerance, and reduction in islet hyperplasia [196].

Recently, fibroblast growth factor 1 (FGF1) was observed as a target of nuclear receptor PPAR- $\gamma$ as a critical factor in adipose remodeling. Administration of recombinant FGF1 ameliorated hepatic inflammation and damage in leptin-deficient ob/ob mice and in choline-deficient mice [197].

There is a close relationship between type 2 diabetes and gene polymorphism of NAFLD. Non-obese NAFLD patients had a higher rs738409 GG genotype than obese NAFLD. Higher incidence of NAFLD was detected in T2DM and rs738409 GG genotype for nonobese than in obese groups. Lobular inflammation, hepatocyte ballooning and NAFLD activity score were observed in non-obese NAFLD, rs738409 GG genotype. In obese NAFLD, BMI and T2DM but not rs738409 GG genotype were characterized by massive histopathological alterations [197].

\section{Conclusion}

The liver is composed of endodermal hepatocytes and mesodermal stromal cells, stellate cells, kuppfer cells and endothelial cells. During in utero life, the hepatocytes have the capability to change into $\beta$-cell. Gestational diabetes induced epigenetic reprogramming and altering gene expression into adulthood causing diabetes. Also, the disease altered the structures and function of cytoplasmic organelles mainly lysosomes, mitochondria, Golgi apparatus and rough endoplasmic reticulum leading to de nevo lipogenesis and development in nonalcohol fatty liver disease. Nonalcoholic fatty liver disease (NAFLD) is a chronic liver disease characterized by excess accumulation of lipids including triglycerides and cholesterol prevailed among patients with type 2 diabetes. There are many views of disease development such as

Obesity, inhibition of SIRT1 signaling in human fetal hepatocytes led to de novo lipogenesis and gluconeogenesis, intra-uterine obesity and malnutrition, overexpression of peroxisome proliferator-activated receptor- $\gamma$ co-activator (PGC-1 $\alpha$ ) altering the regulation of cellular energy metabolism via stimulating mitochondrial biogenesis. The roles of cytoplasmic organelles are illustrated. Beside different approaches of drug therapy, recently different approaches are recommended for treating the non-alcoholic fatty liver such as phytochemical extracts of some plants such as glycyrrhizin, Gynostemma pentaphyllum, astaxanthin,....etc. Also, inhibition of autophagy process and development of $\alpha$-SMA, TGF- $\beta 1$, TNF- $\alpha$ and MCP- 1 in liver tissue as well as promoting mitochondrial function represent new tools. Gene involved in inducing NAFLD as well as gene therapy are discussed. Finally, exercise possessed greater improvements of diabetes and NAFLD in obese individuals.

\section{References}

1. Barker DJ, Osmond C, Golding J, Kuh D, Wadsworth ME (1989) Growth in utero, blood pressure in childhood and adult life, and mortality from cardiovascular disease. BMJ 298: 564-567.

2. Zhao R, Duncan SA (2005) Embryonic development of the liver. Hepatology 41: 956-967.

3. Zaret KS (2008) Genetic programming of liver and pancreas progenitors: lessons for stem-cell differentiation. Nat Rev Genet 9: 329-340.

4. Bort R, Signore M, Tremblay K, Martinez Barbera JP, Zaret KS (2006) Hex homeobox gene controls the transition of the endoderm to a pseudostratified, cell emergent epithelium for liver bud development. Dev Biol 290: 44-56.

5. Shiojiri N, Sugiyama Y (2004) Immunolocalization of extracellular matrix components and integrins during mouse liver development. Hepatology 40: 346-355

6. Martínez N, White V, Kurtz M, Higa R, Capobianco E, et al. (2011) Activation of the nuclear receptor PPARÎ \pm regulates lipid metabolism in foetal liver from diabetic rats: implications in diabetes-induced foetal overgrowth. Diabetes Metab Res Rev 27: 35-46.

7. Petkov PM, Zavadil J, Goetz D, Chu T, Carver R, et al. (2004) Gene expression pattern in hepatic stem/progenitor cells during rat fetal development using complementary DNA microarrays. Hepatology 39: 617-627.

8. Goldman O, Han S, Hamou W, Jodon de Villeroche V, Uzan G, et al. (2014) Endoderm generates endothelial cells during liver development. Stem Cell Reports 3: 556-565.

9. Lemaigre FP (2003) Development of the biliary tract. Mech Dev 120: 81-87.

10. Desmet VJ (2005) [Cystic diseases of the liver. From embryology to malformations]. Gastroenterol Clin Biol 29: 858-860.

11. Conforto TL, Waxman DJ (2012) Sex-specific mouse liver gene expression: genome-wide analysis of developmental changes from prepubertal period to young adulthood. Biol Sex Differ 3: 9.

12. Shaw JE, Sicree RA, Zimmet PZ (2010) Global estimates of the prevalence of diabetes for 2010 and 2030. Diabetes Res Clin Pract 87: 4-14.

13. Kim SM, Lee JS, Lee J, Na JK, Han JH, et al. (2006) Prevalence of diabetes and impaired fasting glucose in Korea: Korean National Health and Nutrition Survey 2001. Diabetes Care 29: 226-231.

14. Kenko Eiyo Joho Kenkyukai (2010) The national health and nutrition survey in Japan, 2007.] Tokyo, Japan: Daiichi-shuppan.

15. Thomas F, Balkau B, Vauzelle-Kervroedan F, Papoz L (1994) Maternal effect and familial aggregation in NIDDM. The CODIAB Study. CODIAB-INSERM-ZENECA Study Group. Diabetes 43: 63-67.

16. McLean M, Chipps D, Cheung NW (2006) Mother to child transmission of diabetes mellitus: does gestational diabetes program Type 2 diabetes in the next generation? Diabet Med 23: 1213-1215.

17. StanÄ $\tilde{A}_{i} \operatorname{kov} \tilde{A}_{i} A$, Laakso M (2016) Genetics of Type 2 Diabetes. Endocr Dev 31: 203-220.

18. Padmanabhan S, Jiang S, Mclean M, et al. (2016) Effect of pregnancy on insulin requirements differs between type 1 and type 2 diabetes: A cohort study of 222 pregnancies. Aust N Z J Obstet Gynaecol 56: 352-357.

19. Clausen TD, Mathiesen E, Ekbom P, Hellmuth E, Mandrup-Poulsen T, et al. (2005) Poor pregnancy outcome in women with type 2 diabetes. Diabetes Care 28: 323-328.

20. Giorgio V, Prono F, Graziano F, Nobili V (2013) Pediatric non alcoholic fatty liver disease: old and new concepts on development, progression, metabolic insight and potential treatment targets. BMC Pediatrics 13:40.

21. Firneisz G (2014) Non-alcoholic fatty liver disease and type 2 diabetes mellitus: the liver disease of our age? World J Gastroenterol 20: 9072-9089.

22. Dyson JK, Anstee Q M, McPherson S (2014) Non-alcoholic fatty liver disease: a practical approach to treatment. Frontline Gastroenterol 0:110 . 
23. Anderson EL, Howe LD, Jones HE, Higgins JP, Lawlor DA, et al. (2015) The Prevalence of Non-Alcoholic Fatty Liver Disease in Children and Adolescents: A Systematic Review and Meta-Analysis. PLoS ONE 10: e0140908.

24. Friedman JE (2016) The early origins of NAFLD in humans and nonhuman primates. FASEB J 30 (1): 257.

25. El-Sayyad HI, Al-Haggar MM, El-Ghawet HA, Bakr IH (2014) Effect of maternal diabetes and hypercholesterolemia on fetal liver of albino Wistar rats. Nutrition 30: 326-336.

26. Birkenfeld AL, Shulman GI (2014) Nonalcoholic fatty liver disease, hepatic insulin resistance, and type 2 diabetes. Hepatology 59: 713-723.

27. Adams LA, Waters OR, Knuiman MW, Elliott RR, Olynyk JK (2009) NAFLD as a risk factor for the development of diabetes and the metabolic syndrome: an eleven-year follow-up study. Am J Gastroenterol 104: 861-867.

28. Postic C, Girard J (2008) The role of the lipogenic pathway in the development of hepatic steatosis. Diabetes Metab 34: 643-648.

29. Roden M (2006) Mechanisms of Disease: hepatic steatosis in type 2 diabetes--pathogenesis and clinical relevance. Nat Clin Pract Endocrinol Metab 2: 335-348.

30. Cusi K (2009) Nonalcoholic fatty liver disease in type 2 diabetes mellitus. Curr Opin Endocrinol Diabetes Obes 16: 141-149.

31. Marra F, Gastaldelli A, Svegliati Baroni G, Tell G, Tiribelli C (2008) Molecular basis and mechanisms of progression of non-alcoholic steatohepatitis. Trends Mol Med 14: 72-81.

32. Fleischman MW1, Budoff M1, Zeb I1, Li D1, Foster T1 (2014) NAFLD prevalence differs among hispanic subgroups: the Multi-Ethnic Study of Atherosclerosis. World J Gastroenterol 20: 4987-4993.

33. Firneisz G (2014) Non-alcoholic fatty liver disease and type 2 diabetes mellitus: the liver disease of our age? World J Gastroenterol 20: 9072-9089.

34. Fracanzani AL, Valenti L, Bugianesi E, Andreoletti M, Colli A, et al. (2008) Risk of severe liver disease in nonalcoholic fatty liver disease with normal aminotransferase levels: a role for insulin resistance and diabetes. Hepatology 48: 792-798

35. Somalwar AM, Raut AD (2014) Study of association of non alcoholic fatty liver disease (NAFLD) with micro and macrovascular complications of type 2 diabetes mellitus (T2DM). Int J Res Med Sci 2(2): 493-497.

36. Ferreira VS, Pernambuco RB, Lopes EP, Morais CN, Rodrigues MC, et al. (2010) Frequency and risk factors associated with non-alcoholic fatty liver disease in patients with type 2 diabetes mellitus. Arq Bras Endocrinol Metabol 54: 362-368.

37. Liu H, Shao-Gang M, Liang C, Feng B, Wei X (2015) Surrogate markers of the kidney and liver in the assessment of gestational diabetes mellitus and fetal outcome. J Clin Diagn Res 9: OC14-17.

38. Poston L (2011) Intergenerational transmission of insulin resistance and type 2 diabetes. Prog Biophys Mol Biol 106: 315-322.

39. Patel KR, White FV, Deutsch GH (2015) Hepatic steatosis is prevalent in stillborns delivered to women with diabetes mellitus. J Pediatr Gastroenterol Nutr 60: 152-158.

40. Tobita T, Guzman-Lepe J, Takeishi K, Nakao T, Wang Y, et al. (2016) SIRT1 Disruption in Human Fetal Hepatocytes Leads to Increased Accumulation of Glucose and Lipids. PLoS ONE 11: e0149344.

41. Saad M, Abdelkhalek TM, Haiba MM, Saleh MM, Hanafi MY, et al (2015) Maternal obesity and malnourishment exacerbate perinatal oxidative stress resulting in diabetogenic programming in F1 offspring. J Endocrinol Invest 39(6):643-55.

42. Auboeuf D, Rieusset J, Fajas L, Vallier P, Frering V, et al. (1997) Tissue distribution and quantification of the expression of mRNAs of peroxisome proliferator-activated receptors and liver X receptor-alpha in humans: no alteration in adipose tissue of obese and NIDDM patients. Diabetes. 46(8):1319-1327.

43. Louet JF, Chatelain F, Decaux JF, Park EA, Kohl C, et al. (2001) Longchain fatty acids regulate liver carnitine palmitoyltransferase I gene (L-
CPT I) expression through a peroxisome-proliferator-activated receptor alpha (PPARalpha)-independent pathway. Biochem J 354: 189-197.

44. Tontonoz P, Spiegelman BM (2008) Fat and beyond: the diverse biology of PPARgamma. Annu Rev Biochem 77: 289-312.

45. Besseiche A, Riveline JP, Gautier JF, Bréant B, Blondeau B (2015) Metabolic roles of PGC-1 $1 \hat{\mathrm{I}} \pm$ and its implications for type 2 diabetes. Diabetes Metab 41: 347-357.

46. Hashimoto K1 (2015) Epigenomic Regulation of Hepatic Lipid Metabolism and Its Clinical Application. J Nutr Sci Vitaminol (Tokyo) 61 Suppl:S81.

47. Stewart MS1, Heerwagen MJ, Friedman JE (2013) Developmental programming of pediatric nonalcoholic fatty liver disease: redefining the"first hit". Clin Obstet Gynecol 56: 577-590.

48. Pruis MG1, Lendvai A, Bloks VW, Zwier MV, Baller JF, et al. (2014) Maternal western diet primes non-alcoholic fatty liver disease in adult mouse offspring. Acta Physiol (Oxf) 210: 215-227.

49. Lin YC, Chang PF, Chang MH, Ni YH (2013) A common variant in the peroxisome proliferator-activated receptor-? coactivator-1a gene is associated with nonalcoholic fatty liver disease in obese children. Am J Clin Nutr 97(2):326-331

50. Soyal S, Krempler F, Oberkofler H, Patsch W (2006) PGC-1alpha: a potent transcriptional cofactor involved in the pathogenesis of type 2 diabetes. Diabetologia 49: 1477-1488.

51. McCurdy CE, Bishop JM, Williams SM, Grayson BE, Smith MS, et al. (2009) Maternal high-fat diet triggers lipotoxicity in the fetal livers of nonhuman primates. J Clin Invest 119: 323-335.

52. Brumbaugh DE, Friedman JE (2014) Developmental origins of nonalcoholic fatty liver disease. Pediatr Res 75: 140-147.

53. El-Sayyad HIH, El-Shershaby EM, Saleh DF (2013) Effects of experimental diabetes and gliclazide on pregnant albino rats and their pups. JIMR 1(1):22-29.

54. von Wnuck Lipinski K, Sattler K, Peters S, Weske S, et al.(2016) Hepatocyte Nuclear Factor 1A Is a Cell-Intrinsic Transcription Factor Required for B Cell Differentiation and Development in Mice. J Immunol. 196(4):1655-1665.

55. Ugalde-Nicalo PA1, Schwimmer JB (2015) On the origin of pediatric nonalcoholic Fatty liver disease. J Pediatr Gastroenterol Nutr 60: 147-148.

56. Brumbaugh DE, Tearse P, Cree-Green M, Fenton LZ, Brown M, et al. (2013) Intrahepatic fat is increased in the neonatal offspring of obese women with gestational diabetes. J Pediatr 162: 930-936.

57. Patel KR, White FV, Deutsch GH (2015) Hepatic steatosis is prevalent in stillborns delivered to women with diabetes mellitus. J Pediatr Gastroenterol Nutr 60: 152-158.

58. Kamimae-Lanning AN, Krasnow SM2, Goloviznina NA3, Zhu X2, RothCarter QR4, et al. (2014) Maternal high-fat diet and obesity compromise fetal hematopoiesis. Mol Metab 4: 25-38.

59. Day CP (2010) Genetic and environmental susceptibility to non-alcoholic fatty liver disease. Dig Dis 28: 255-260.

60. Albayrak A, Uyanik MH, Cerrah S, Altas S, Dursun H, et al. (2010) Is HMGB1 a new indirect marker for revealing fibrosis in chronic hepatitis and a new therapeutic target in treatment? Viral Immunol 23: 633-638.

61. Woods SC, Porte D Jr (1974) Neural control of the endocrine pancreas. Physiol Rev 54: 596-619.

62. Ahrén B (2000) Autonomic regulation of islet hormone secretion-implications for health and disease. Diabetologia 43: 393-410.

63. Grant WF, Nicol LE, Thorn SR, Grove KL, Friedman JE, et al. (2012) Perinatal exposure to a high-fat diet is associated with reduced hepatic sympathetic innervation in one-year old male Japanese macaques. PLoS ONE 7: e48119.

64. Borden P, Houtz J, Leach SD, Kuruvilla R (2013) Sympathetic innervation during development is necessary for pancreatic islet architecture and functional maturation. Cell Rep 25: 4(2): 287-301.

65. Liu YQ, Jetton TL, Leahy JL (2002) beta-Cell adaptation to insulin resistance. Increased pyruvate carboxylase and malate-pyruvate shuttle 
activity in islets of nondiabetic Zucker fatty rats. J Biol Chem 277: 39163-39168.

66. Butler AE, Janson J, Bonner-Weir S, Ritzel R, Rizza RA, et al. (2003) Betacell deficit and increased beta-cell apoptosis in humans with type 2 diabetes. Diabetes 52: 102-110.

67. Linnemann AK, Baan M, Davis DB (2014) Pancreatic $\hat{I}^{2}$-cell proliferation in obesity. Adv Nutr 5: 278-288.

68. Peyot ML, Pepin E, Lamontagne J, Latour MG, Zarrouki B, et al. (2010) Beta-cell failure in diet-induced obese mice stratified according to body weight gain: secretory dysfunction and altered islet lipid metabolism without steatosis or reduced beta-cell mass. Diabetes 59: 2178-2187.

69. Roat R, Rao V, Doliba NM, Matschinsky FM, Tobias JW, et al. (2014) Alterations of pancreatic islet structure, metabolism and gene expression in diet-induced obese C57BL/6J mice. PLoS ONE 9: e86815.

70. Ahmed M, de Winther MP, Van den Bossche J (2016) Epigenetic mechanisms of macrophage activation in type 2 diabetes. Immunobiology .

71. Shimabukuro M, Higa M, Zhou YT, Wang MY, Newgard CB, et al. (1998) Lipoapoptosis in beta-cells of obese prediabetic fa/fa rats. Role of serine palmitoyltransferase overexpression. J Biol Chem 273: 32487-32490.

72. Golay A, Ybarra J (2005) Link between obesity and type 2 diabetes. Best Pract Res Clin Endocrinol Metab 19: 649-663.

73. Loomba R, Sirlin CB, Schwimmer JB, Lavine JE (2009) Advances in pediatric nonalcoholic fatty liver disease. Hepatology 50: 1282-1293.

74. Lee JS, Zheng Z, Mendez R, Ha SW, Xie Y, et al. (2012) Pharmacologic ER stress induces non-alcoholic steatohepatitis in an animal model. Toxicol Lett 211: 29-38.

75. Pagliassotti MJ (2012) Endoplasmic reticulum stress in nonalcoholic fatty liver disease. Annu Rev Nutr 32: 17-33.

76. Li XL, Zhou AG (2012) Evaluation of the immunity activity of glycyrrhizin in AR mice. Molecules 17: 716-727.

77. Nakahara $T$, Hindsgaul O, Palcic MM, Nishimura S(2006). Computational design and experimental evaluation of glycosyltransferase mutants: engineering of a blood type $\mathrm{B}$ galactosyltransferase with enhanced glucosyltransferase activity. Protein Eng Des Sel 19:571-578.

78. Zhan YT, Su HY, An W (2016) Glycosyltransferases and non-alcoholic fatty liver disease. World J Gastroenterol 22: 2483-2493.

79. Breton C, Snajdrová L, Jeanneau C, Koca J, Imberty A (2006) Structures and mechanisms of glycosyltransferases. Glycobiology 16: 29R-37R.

80. Quintero CA, Giraudo CG, Villarreal M, Montich G, Maccioni HJ (2010) Identification of a site in Sar1 involved in the interaction with the cytoplasmic tail of glycolipid glycosyltransferases. J Biol Chem 285: 30340-30346.

81. Westermeier F, Sáez PJ, Villalobos-Labra R, Sobrevia L, Farías-Jofré M (2014) Programming of fetal insulin resistance in pregnancies with maternal obesity by ER stress and inflammation. Biomed Res Int 2014: 917672 .

82. Zhang S, Liu X, Brickman WJ, Christoffel KK, Zimmerman D, et al (2009) Association of plasma leptin concentrations with adiposity measurements in rural Chinese adolescents. J Clin Endocrinol Metab 94: 3497-3504.

83. Levine B, Klionsky DJ (2004) Development by self-digestion: molecular mechanisms and biological functions of autophagy. Dev Cell 6: 463-477.

84. Feldstein AE, Werneburg NW, Canbay A, Guicciardi ME, Bronk SF, et al. (2004) Free fatty acids promote hepatic lipotoxicity by stimulating TNFalpha expression via a lysosomal pathway. Hepatology 40: 185-194.

85. Li Z, Berk M, McIntyre TM, Gores GJ, Feldstein AE (2008) The lysosomal-mitochondrial axis in free fatty acid-induced hepatic lipotoxicity. Hepatology 47: 1495-1503.

86. Kwanten WJ, Martinet W, Michielsen PP, Francque SM (2014) Role of autophagy in the pathophysiology of nonalcoholic fatty liver disease: a controversial issue. World J Gastroenterol 20: 7325-7338.

87. Samuel VT, Petersen KF, Shulman GI (2010) Lipid-induced insulin resistance: unravelling the mechanism. Lancet 375: 2267-2277.
88. Hendrikx T, Walenbergh SM, Hofker MH, Shiri-Sverdlov R (2014) Lysosomal cholesterol accumulation: driver on the road to inflammation during atherosclerosis and non-alcoholic steatohepatitis. Obes Rev 15: 424-433.

89. El-Sayyad HIH (2016) Cellular cholesterol retention in atherosclerosis.Human health handbooks, Volume 11, Editors Ronald Ross Watson and Fabien De Meester. DOI 2016:

90. Mizushima N, Levine B, Cuervo AM, Klionsky DJ (2008) Autophagy fights disease through cellular self-digestion. Nature 451: 1069-1075.

91. Miwa S, Lawless C, von Zglinicki T (2008) Mitochondrial turnover in liver is fast in vivo and is accelerated by dietary restriction: application of a simple dynamic model. Aging Cell 7: 920-923.

92. Dey A, Swaminathan K (2010) Hyperglycemia-induced mitochondrial alterations in liver. Life Sci 87: 197-214.

93. Ahishali E, Demir K, Ahishali B, Akyuz F, Pinarbasi B, et al. (2010) Electron microscopic findings in non-alcoholic fatty liver disease: is there a difference between hepatosteatosis and steatohepatitis?. J Gastroenterol Hepatol. 25(3):619-626.

94. Gambino R, Musso G, Cassader M (2011) Redox balance in the pathogenesis of nonalcoholic fatty liver disease: mechanisms and therapeutic opportunities. Antioxid Redox Signal 15: 1325-1365.

95. Valle A, Catalán V, Rodríguez A, Rotellar F, Valentí V, et al. (2012) Identification of liver proteins altered by type 2 diabetes mellitus in obese subjects. Liver Int 32: 951-961.

96. Lotowska JM, Sobaniec-Lotowska ME, Lebensztejn DM (2013) The role of Kupffer cells in the morphogenesis of nonalcoholic steatohepatitis ultrastructural findings. The first report in pediatric patients. Scand J Gastroenterol 48: 352-357.

97. Bieghs V, Hendrikx T, van Gorp PJ, Verheyen F, Guichot YD, et al. (2013) The cholesterol derivative 27-hydroxycholesterol reduces steatohepatitis in mice. Gastroenterology 144: 167-178.

98. Han J, Li E, Chen L, Zhang Y, Wei F, et al. (2015) The CREB coactivator CRTC2 controls hepatic lipid metabolism by regulating SREBP1. Nature 524: $243-246$.

99. Liu J, Ma KL, Zhang Y, Wu Y, Hu ZB, et al. (2015) Activation of mTORC1 disrupted LDL receptor pathway: a potential new mechanism for the progression of non-alcoholic fatty liver disease. Int J Biochem Cell Biol 61: 8-19.

100. Zelber-Sagi S, Nitzan-Kaluski D, Goldsmith R, Webb M, Blendis L, et al. (2007) Long term nutritional intake and the risk for non-alcoholic fatty liver disease (NAFLD): a population based study. J Hepatol 47: 711-717.

101. Bang S, Chen Y, Ahima RS, Kim SF (2014) Convergence of IPMK and LKB1-AMPK signaling pathways on metformin action. Mol Endocrinol 28: 1186-1193.

102. Kohjima M, Higuchi N, Kato M, Kotoh K, Yoshimoto T, et al. (2008) SREBP-1c,regulated by the insulin and AMPK signalling pathways plays a role in nonalcoholic fatty liver disease. Int J Mol Med 21: 507-511.

103. Woo SL,Wu C(2014) Metformin improves aspects of obesity associated NAFLD. Immunoendocrinology 1: e280.

104. Bailey CJ, Bagdonas A, Rubes J, McMorn SO, Donaldson J, et al. (2005) Rosiglitazone/metformin fixed-dose combination compared with uptitrated metformin alone in type 2 diabetes mellitus: a 24-week, multicenter, randomized, double-blind, parallel-group study. Clin Ther 27: $1548-1561$.

105. Komoroski B, Vachharajani N, Feng Y, Li L, Kornhauser D, et al. (2009) Dapagliflozin, a novel, selective SGLT2 inhibitor, improved glycemic control over 2 weeks in patients with type 2 diabetes mellitus. Clin Pharmacol Ther 85: 513-519.

106. DeFronzo RA, Hissa MN, Garber AJ, Luiz Gross J, Yuyan Duan R, et al. (2009) The efficacy and safety of saxagliptin when added to metformin therapy in patients with inadequately controlled type 2 diabetes with metformin alone. Diabetes Care 32: 1649-1655.

107. Linden MA, Fletcher JA, Morris EM, Meers GM,Kearney ML, et al. (2014) Combining metformin and aerobic exercise training in the 
treatment of type 2 diabetes and NAFLD in OLETF rats. Am J Physiol Endocrinol Metab 306: E300-310.

108. Soccio RE, Chen ER, Lazar MA2 (2014) Thiazolidinediones and the promise of insulin sensitization in type 2 diabetes. Cell Metab 20: 573-591.

109. Yokoi $T$ (2010) Troglitazone Handb Exp Pharmacol . 419-435.

110. Jones SA, Moore LB, Shenk JL, Wisely GB, Hamilton GA, et al. (2000) The pregnane $\mathrm{X}$ receptor: a promiscuous xenobiotic receptor that has diverged during evolution. Mol Endocrinol 14: 27-39.

111. Hauner H (2002) The mode of action of thiazolidinediones. Diabetes Metab Res Rev 18: S10-15.

112. Chang E, Park CY2, Park SW2 (2013) Role of thiazolidinediones, insulin sensitizers, in non-alcoholic fatty liver disease. J Diabetes Investig 4: 517-524.

113. Yang L, Song MQ1, Zhang QL1, Shou L1, Zang SF1, et al. (2014) Effect of piglitazone and metformin on retinol-binding protein-4 and adiponectin in patients with type 2 diabetes mellitus complicated with non-alcohol fatty acid liver diseases. Zhongguo Yi Xue Ke Xue Yuan Xue Bao 36: 309-312.

114. Surapaneni KM, Priya VV, Mallika J (2014) Pioglitazone, quercetin and hydroxy citric acid effect on cytochrome P450 2E1(CYP2E1) enzyme levels in experimentally induced non alcoholic steatohepatitis (NASH). Eur Rev Med Pharmacol Sci 18: 2736-2741.

115. García Díaz E, Guagnozzi D, Gutiérrez V, Mendoza C, Maza C, et al. (2016) Effect of incretin therapies compared to pioglitazone and gliclazide in non-alcoholic fatty liver disease in diabetic patients not controlled on metformin alone: An observational, pilot study. Endocrinol Nutr 63: 194-201.

116. Ratziu V, Giral P, Jacqueminet S, Charlotte F, Hartemann-Heurtier A, et al. (2008) Rosiglitazone for nonalcoholic steatohepatitis: one-year results of the randomized placebo-controlled Fatty Liver Improvement with Rosiglitazone Therapy (FLIRT) Trial. Gastroenterology 135: 100-110.

117. Torres DM, Jones FJ, Shaw JC, Williams CD, Ward JA, et al. (2011) Rosiglitazone versus rosiglitazone and metformin versus rosiglitazone and losartan in the treatment of nonalcoholic steatohepatitis in humans: a 12-month randomized, prospective, open- label trial. Hepatology 54: 1631-1639.

118. Promrat K, Lutchman G, Uwaifo GI, Freedman RJ, Soza A, et al. (2004) A pilot study of pioglitazone treatment for nonalcoholic steatohepatitis. Hepatology 39: 188-196.

119. Sanyal AJ, Mofrad PS, Contos MJ, Sargeant C, Luketic VA, et al. (2004) A pilot study of vitamin E versus vitamin $\mathrm{E}$ and pioglitazone for the treatment of nonalcoholic steatohepatitis. Clin Gastroenterol Hepatol 2: 1107-1115.

120. Dima A, Marinescu AG, Dima AC (2012) Non-alcoholic fatty liver disease and the statins treatment. Rom J Intern Med 50: 19-25.

121. Kiyici M, Gulten M, Gurel S, Nak SG, Dolar E, et al. (2003) Ursodeoxycholic acid and atorvastatin in the treatment of nonalcoholic steatohepatitis. Can J Gastroenterol 17: 713-718.

122. Antonopoulos S, Mikros S, Mylonopoulou M, Kokkoris S, Giannoulis G (2006) Rosuvastatin as a novel treatment of non-alcoholic fatty liver disease in hyperlipidemic patients. Atherosclerosis 184: 233-234.

123. Hui JM, Hodge A, Farrell GC, Kench JG, Kriketos A, et al. (2004) Beyond insulin resistance in NASH: TNF-alpha or adiponectin? Hepatology 40: 46-54.

124. Yoneda M, Mawatari H, Fujita K, Iida H, Yonemitsu K, et al.(2007) Highsensitivity C-reactive protein is an independent clinical feature of nonalcoholic steatohepatitis (NASH) and also of the severity of fibrosis in NASH. J Gastroenterol 42: 573-582.

125. Lonardo A, Lombardini S, Ricchi M, Scaglioni F, Loria P (2005) Hepatic steatosis and insulin resistance. Aliment Pharmacol Ther 22: 64-70.

126. Sugiyama S, Fukushima H, Kugiyama K, Maruyoshi H, Kojima S, et al. (2007) Pravastatin improved glucose metabolism associated with increasing plasma adiponectin in patients with impaired glucose tolerance and coronary artery disease. Atherosclerosis 194: e43-51.
127. Polyzos SA, Kountouras J, Zavos C, Tsiaousi E (2010) The role of adiponectin in the pathogenesis and treatment of non-alcoholic fatty liver disease. Diabetes Obes Metab 12: 365-383.

128. Filippatos TD (2012) A review of time courses and predictors of lipid changes with fenofibric acid-statin combination. Cardiovasc Drugs Ther 26: 245-255.

129. Belfort R, Berria R, Cornell J, Cusi K (2010) Fenofibrate reduces systemic inflammation markers independent of its effects on lipid and glucose metabolism in patients with the metabolic syndrome. J Clin Endocrinol Metab 95: 829-836.

130. Fatani S, Itua I, Clark P, Wong C, Naderali EK (2011) The effects of dietinduced obesity on hepatocyte insulin signaling pathways and induction of non-alcoholic liver damage. Int J Gen Med 4: 211-219.

131. Shiri-Sverdlov R, Wouters K, van Gorp PJ, Gijbels MJ, Noel B, et al. (2006) Early diet-induced non-alcoholic steatohepatitis in APOE2 knockin mice and its prevention by fibrates. J Hepatol 44: 732-741.

132. Seo YS, Kim JH, Jo NY, Choi KM, Baik SH, et al.(2008) PPAR agonists treatment is effective in a nonalcoholic fatty liver disease animal model by modulating fatty-acid metabolic enzymes. J Gastroenterol Hepatol. 23: 102-109.

133. Kostapanos MS, Kei A, Elisaf MS (2013) Current role of fenofibrate in the prevention and management of non-alcoholic fatty liver disease. World J Hepatol 5: 470-478.

134. Magliano DC, Bargut TC, de Carvalho SN, Aguila MB, Mandarim-deLacerda CA, et al.(2013) Peroxisome proliferator-activated receptorsalpha and gamma are targets to treat offspring from maternal dietinduced obesity in mice. PLoS One8: e64258.

135. Leung CCH, Young KK (2015) Clinical aspects of hepatic disease. Anaesth. Intensive Care Med 16: 11-,et13.

136. Edwards L, Wanless IR (2013) Mechanisms of liver involvement in systemic disease. Best Pract Res Clin Gastroenterol 27: 471-483.

137. Vernon G, Baranova A, Younossi ZM (2011) Systematic review: the epidemiology and natural history of non-alcoholic fatty liver disease and non-alcoholic steatohepatitis in adults. Aliment Pharmacol Ther 34: 274-285.

138. Rafieian-Kopaei M, Baradaran A, Rafieian M (2013) Oxidative stress and the paradoxical effects of antioxidants. J Res Med Sci 18: 629.

139. Halliwell B (2012) Free radicals and antioxidants: updating a personal view. Nutr Rev 70: 257-265.

140. Savini I, Catani MV, Evangelista D, Gasperi V, Avigliano L (2013) Obesity-associated oxidative stress: strategies finalized to improve redox state. Int J Mol Sci 14: 10497-10538.

141. Serra D, Mera P, Malandrino MI, Mir JF, Herrero L,et al. (2013) Mitochondrial fatty acid oxidation in obesity. Antioxid Redox Signal 19: 269-284.

142. Rahimi RS, Landaverde C (2013) Nonalcoholic fatty liver disease and the metabolic syndrome: clinical implications and treatment. Nutr Clin Pract 28: 40-51.

143. Wang CY, Kao TC, Lo WH, Yen GC (2011) Glycyrrhizic acid and 18ßglycyrrhetinic acid modulate lipopolysaccharide-induced inflammatory response by suppression of NF-?B through PI3K p110d and p110? inhibitions. J Agric. Food Chem 59: 7726-7733.

144. Wu X, Zhang L, Gurley E, Studer E, Shang J, et al. (2008) Prevention of free fatty acid-induced hepatic lipotoxicity by 18 beta-glycyrrhetinic acid through lysosomal and mitochondrial pathways. Hepatology 47: 1905-1915.

145. Hajiaghamohammadi AA, Ziaee A, Samimi R (2012) The efficacy of licorice root extract in decreasing transaminase activities in non-alcoholic fatty liver disease: a randomized controlled clinical trial. Phytother Res 26: $1381-1384$

146. Sil R, Chakraborti AS (2013) Glycyrrhizin ameliorates insulin resistance, hyperglycemia, dyslipidemia and oxidative stress in fructose-induced metabolic syndrome-X in rat model. Ind. J. EXp. BIol. 51:129-138. 
147. Huyen VT, Phan DV, Thang P, Hoa NK, Ostenson CG (2010) Antidiabetic effect of Gynostemma pentaphyllum tea in randomly assigned type 2 diabetic patients. Horm Metab Res 42: 353-357.

148. Gao D, Zhao M, Qi X, Liu Y, Li N, et al. (2016) Hypoglycemic effect of Gynostemma pentaphyllum saponins by enhancing the Nrf2 signaling pathway in STZ-inducing diabetic rats. Arch Pharm Res 39: 221-230.

149. Malek MA, Hoang MH, Jia Y, Lee JH, Jun HJ, et al.(2013) Ombuin-3-Oß-D-glucopyranoside from Gynostemma pentaphyllum is a dual agonistic ligand of peroxisome proliferator-activated receptors a and $\mathrm{d} / \mathrm{B}$. Biochem. Biophys. Res. Commun 430: 1322-1328.

150. Al-Shaaibi SN, Waly MI, Al-Subhi L, Tageldin MH, Al-Balushi NM, et al. (2016) Ameliorative Effects of Pomegranate Peel Extract against DietaryInduced Nonalcoholic Fatty Liver in Rats. Prev Nutr Food Sci 21: 14-23.

151. Lotito SB, Frei B (2006) Consumption of flavonoid-rich foods and increased plasma antioxidant capacity in humans: cause, consequence, or epiphenomenon? Free Radic Biol Med 4: 1727-1746.

152. Li X, Wang R, Zhou N, Wang X, Liu Q, et al. (2013) Quercetin improves insulin resistance and hepatic lipid accumulation in vitro in a NAFLD cell model. Biomed Rep 1: 71-76.

153. Zhou DS, Liang ZQ, Qin Q, Zhang MH, Li SL (2013) Therapeutic efficacy and mechanisms of quercetin in a rat model of nonalcoholic fatty liver disease. Zhonghua Gan Zang Bing Za Zhi 21: 134-137.

154. Ragab SM, Abd Elghaffar SKh, El-Metwally TH, Badr G, Mahmoud MH, et al. (2015) Effect of a high fat, high sucrose diet on the promotion of non-alcoholic fatty liver disease in male rats: the ameliorative role of three natural compounds. Lipids Health Dis 14: 83.

155. Choi H, Jeong S, Huh GH, Kim JI (2015) Quercetin ameliorates insulin sensitivity and liver steatosis partly by increasing adiponectin expression in ob/ob mice. Quercetin. Food Sci Biotechnol 24: 273-279.

156. Pisonero-Vaquero S, Martínez-Ferreras Á, García-Mediavilla MV, Martínez-Flórez S, Fernández A, et al. (2015) Quercetin ameliorates dysregulation of lipid metabolism genes via the PI3K/AKT pathway in a diet-induced mouse model of nonalcoholic fatty liver disease. Mol Nutr Food Res 59: 879-893.

157. Ann JW, Eo H, and Lim Y (2015) Mulberry leaves (Morus alba L.) ameliorate obesity-induced hepatic lipogenesis, fibrosis, and oxidative stress in high-fat diet-fed mice. Genes Nutr 10: 4-6.

158. Jang HH, Park MY, Kim HW, Lee YM, Hwang KA, et al. (2012) Black rice (Oryza sativa L.) extract attenuates hepatic steatosis in C57BL/6 J mice fed a high-fat diet via fatty acid oxidation. Nutr Metab (Lond) 9: 1-27.

159. Choi JS, Kim H, Jung MH, Hong S, Song J (2010) Consumption of barley beta-glucan ameliorates fatty liver and insulin resistance in mice fed a high-fat diet. Mol Nutr Food Res 54: 1004-1013.

160. Al-Shaaibi SN, Waly MI, Al-Subhi L, Tageldin MH, Al-Balushi NM, et al. (2016) Ameliorative Effects of Pomegranate Peel Extract against DietaryInduced Nonalcoholic Fatty Liver in Rats. Prev Nutr Food Sci 21: 14-23.

161. Ekhlasi G, Shidfar F, Agah S, Merat S, Hosseini AF (2016) Effects of Pomegranate and Orange Juice on Antioxidant Status in Non-Alcoholic Fatty Liver Disease Patients: A Randomized Clinical Trial. Int J Vitam Nutr Res 14: 1-7.

162. Nobili V, Alisi A, Musso G, Scorletti E, et al. (2016) Omega-3 fatty acids: Mechanisms of benefit and therapeutic effects in pediatric and adult NAFLD. Crit Rev Clin Lab Sci 53: 106-120.

163. Faghihzadeh F, Adibi P, Hekmatdoost A (2015) The effects of resveratrol supplementation on cardiovascular risk factors in patients with nonalcoholic fatty liver disease: a randomised, double-blind, placebocontrolled study. Br J Nutr 114: 796-803.

164. Pan QR, Ren YL, Liu WX, Hu YJ, Zheng JS, et al. (2015) Resveratrol prevents hepatic steatosis and endoplasmic reticulum stress and regulates the expression of genes involved in lipid metabolism, insulin resistance, and inflammation in rats. Nutr Res 35: 576-584.

165. Gan L, Meng ZJ, Xiong RB, Guo JQ, Lu XC, et al. (2015) Green tea polyphenol epigallocatechin-3-gallate ameliorates insulin resistance in non-alcoholic fatty liver disease mice. Acta Pharmacol Sin 36: 597-605.
166. Mohamed WS, Mostafa AM, Mohamed KM, Serwah AH (2015) Effects of fenugreek, Nigella, and termis seeds in nonalcoholic fatty liver in obese diabetic albino rats. Arab J Gastroenterol 16: 1-9.

167. Wang ZQ, Zhang XH, Yu Y, Tipton RC, Raskin I, et al. (2013) Artemisia scoparia extract attenuates non-alcoholic fatty liver disease in dietinduced obesity mice by enhancing hepatic insulin and AMPK signaling independently of FGF21 pathway. Metabolism 62: 1239-1249.

168. Emamat H, Foroughi F, Eini-Zinab H, Taghizadeh M, Rismanchi M, et al. (2016) The effects of onion consumption on treatment of metabolic, histologic, and inflammatory features of nonalcoholic fatty liver disease. J Diabetes Metab Disord 22: 15-25.

169. Higuera-Ciapara I1, Félix-Valenzuela L, Goycoolea FM (2006) Astaxanthin: a review of its chemistry and applications. Crit Rev Food Sci Nutr 46: 185-196.

170. Ranga Rao A, Siew Moi P, Ravi S, Aswathanarayana R G (2014) Astaxanthin: sources, extraction, stability, biological activities and its commercial applications a review Mar. Drugs 12: 128-152.

171. Zhu C, Naqvi S, Capell T, Christou P (2009) Metabolic engineering of ketocarotenoid biosynthesis in higher plants. Arch Biochem Biophys 483: 182-190.

172. Naguib YM (2000) Antioxidant activities of astaxanthin and related carotenoids. J Agric Food Chem 48: 1150-1154.

173. Borowitzka MA (2013) High-value products from microalgae their development and commercialisation. J Appl Phycol 25: 743-756.

174. Koller M, Muhr, and Braunegg G (2014) Microalgae as versatile cellular factories for valued products. Algal Res 6: 52-63.

175. Pérez-López P, González-García S, Jeffryes C, Agathos SN, McHugh E, et al. (2014) Life-cycle assessment of the production of the red antioxidant carotenoid astaxanthin by microalgae: from lab to pilot scale. J Clea Prod 64: 332-344.

176. Chen JT, Kotani K (2016) Astaxanthin as a Potential Protector of Liver Function: A Review. J Clin Med Res 8: 701-704.

177. Yoshida H, Yanai H, Ito K, Tomono Y, Koikeda T, et al. (2010) Administration of natural astaxanthin increases serum HDL-cholesterol and adiponectin in subjects with mild hyperlipidemia. Atherosclerosis 209: 520-523.

178. Ikeuchi M, Koyama T, Takahashi J, Yazawa K (2007) Effects of astaxanthin in obese mice fed a high-fat diet. Biosci Biotechnol Biochem 71: 893-899.

179. Yang Y, Kim B, Park YK, Koo SI, Lee JY (2015) Astaxanthin prevents TGFI ${ }^{2} 1$-induced pro-fibrogenic gene expression by inhibiting Smad3 activation in hepatic stellate cells. Biochim Biophys Acta 1850: 178-185.

180. Ni Y, Nagashimada M, Zhuge F, Zhan L, et al. (2015) Astaxanthin prevents and reverses diet-induced insulin resistance and steatohepatitis in mice: A comparison with vitamin E. Sci Rep 5: 17192.

181. Her GM, Pai WY, Lai CY, Hsieh YW, Pang HW (2013) Ubiquitous transcription factor YY1 promotes zebrafish liver steatosis and lipotoxicity by inhibiting CHOP-10 expression. Biochim Biophys Acta 1831: 1037-1051.

182. Kim JE, Clark RM, Park Y, Lee J, Fernandez ML (2012) Lutein decreases oxidative stress and inflammation in liver and eyes of guinea pigs fed a hypercholesterolemic diet. Nutr Res Pract 6: 113-119.

183. Ni Y, Zhuge F, Nagashimada M, Ota T (2016) Novel Action of Carotenoids on Non-Alcoholic Fatty Liver Disease: Macrophage Polarization and Liver Homeostasis. Nutrients 8: 7-391.

184. Anstee QM, Day CP (2015) The Genetics of Nonalcoholic Fatty Liver Disease: Spotlight on PNPLA3 and TM6SF2. Semin Liver Dis 35: 270-290.

185. Dongiovanni P, Anstee QM, Valenti L (2013) Genetic predisposition in NAFLD and NASH: impact on severity of liver disease and response to treatment. Curr Pharm Des 19: 5219-5238.

186. Vilà L, Elias I, Roca C, Ribera A, Ferré T, et al. (2014) AAV8-mediated Sirtl gene transfer to the liver prevents high carbohydrate diet-induced nonalcoholic fatty liver disease. Mol Ther Methods Clin Dev 1: 14039. 
Citation: El-Sayyad HI, El-Shahary EA (2016) Type 2 Diabetes and Developmental Origin of Non-Alcohol Fatty Liver Disease and Future Directions of Treatment. Clin Exp Pharmacol 6: 220. doi:10.4172/2161-1459.1000220

Page 14 of 14

187. Hashemi M, Hanafi Bojd H, Eskandari Nasab E, Bahari A, Hashemzehi NA, et al. (2013) Association of Adiponectin rs1501299 and rs266729 Gene Polymorphisms With Nonalcoholic Fatty Liver Disease. Hepat Mon 13: e9527.

188. Gupta AC, Misra R, Sakhuja P, Singh Y, Basir SF, et al. (2012) Association of adiponectin gene functional polymorphisms $(-11377 \mathrm{C} / \mathrm{G}$ and $+45 \mathrm{~T} / \mathrm{G})$ with nonalcoholic fatty liver disease. Gene 496: 63-67.

189. Liu W, Struik D, Nies VJ, Jurdzinski A, Harkema L, et al. (2016) Effective treatment of steatosis and steatohepatitis by fibroblast growth factor 1 in mouse models of nonalcoholic fatty liver disease. Proc Natl Acad Sci U S A 113: 2288-2293.

190. Zain SM, Mohamed Z, Mahadeva S, Cheah PL, Rampal S, et al. (2013) Impact of leptin receptor gene variants on risk of non-alcoholic fatty liver disease and its interaction with adiponutrin gene. J Gastroenterol Hepatol 28: 873-879.

191. Gonzalez-Rodriguez A, Valverde AM (2015) RNA Interference as a Therapeutic Strategy for the Treatment of Liver Diseases. Curr Pharm Des 21: 4574-4586.

192. Dimitrova-Shumkovska J, Veenman L, Ristoski T, Leschiner S, Gavish M (2010) Chronic high fat, high cholesterol supplementation decreases 18 $\mathrm{kDa}$ Translocator Protein binding capacity in association with increased oxidative stress in rat liver and aorta. Food Chem Toxicol 48: 910-921.
193. Lee YH, Bae SC, Song GG (2014) Meta-analysis of associations between the peroxisome proliferator-activated receptor-gamma Pro12Ala polymorphism and susceptibility to nonalcoholic fatty liver disease, rheumatoid arthritis, and psoriatic arthritis. Genet Test Mole Biomark 18: 341-348.

194. Pereira RR, de Abreu IC, Guerra JF, Lage NN, Lopes JM, et al. (2016) Açai (Euterpe oleracea Mart.) Upregulates Paraoxonase 1 Gene Expression and Activity with Concomitant Reduction of Hepatic Steatosis in High-Fat Diet-Fed Rats. Oxid Med Cell Longev 2016: 1-13.

195. Deng X, Wang J, Jiao L, Utaipan T, Tuma-Kellner S,et al.(2016) iPLA2ß deficiency attenuates obesity and hepatic steatosis in ob/ob mice through hepatic fatty-acyl phospholipid remodeling. Biochim Biophys Acta 1861: 449-461.

196. Lu H, Sun J, Sun L, Shu X, Xu Y, Xie D (2009) Polymorphism of human leptin receptor gene is associated with type 2 diabetic patients complicated with non-alcoholic fatty liver disease in China. J Gastroenterol Hepatol 24: 228-232.

197. Honda Y, Yoneda M, Kessoku T, Ogawa Y, Tomeno W, et al. (2016) Characteristics of non-obese non-alcoholic fatty liver disease: Effect of genetic and environmental factors. Hepatol Res 46: 1011-1018.s 